\title{
Monolithic Interconnected Modules (MIM) for High Irradiance Photovoltaic Energy Conversion: a Comprehensive Review
}

\author{
A. Datas*, P.G. Linares \\ Instituto de Energía Solar, Universidad Politécnica de Madrid, 28040 Madrid, Spain.
}

\begin{abstract}
Monolithic Interconnected Modules (MIM) are densely packed arrays of series interconnected photovoltaic (PV) cells that are manufactured on the same semiconductor substrate. This review presents the result of a prospective study whose objective is to provide an overview of the historical development and current state of the art of the MIM technology. The most outstanding works from the conception of the first MIM devices in the late 70s to the most recent ideas to date, including all relevant milestones achieved during these four decades, are reported. This review focuses on MIM devices that are designed for high-irradiance photovoltaic (HIPV) applications, such as concentrator PV (CPV), thermophotovoltaics (TPV), and laser power conversion (LPC), in which the highly dense series interconnection is particularly relevant in order to boost the output voltage without scarifying the receptor photoactive area.
\end{abstract}




\section{List of Acronyms}

\begin{tabular}{|c|c|}
\hline BPC & Back Point Contact \\
\hline BSR & Back Surface Reflector \\
\hline CID & Cell Isolation Diode \\
\hline CLEFT & Cleavage of Lateral Epitaxy For Transfer \\
\hline $\mathrm{CPV}$ & Concentrator Photovoltaic \\
\hline DH & Double Heterostructure \\
\hline ELO & Epitaxial Lift Off \\
\hline EMVJ & Etched Multiple Vertical Junction \\
\hline FF & Fill Factor \\
\hline GFI & Grid Finger Interconnect \\
\hline GPHS & General Purpose Heat Source \\
\hline HCPV & High Concentrator Photovoltaic \\
\hline HIPV & High Irradiance Photovoltaic \\
\hline HCPVT & High Concentrated Photovoltaic Thermal \\
\hline IMF & Interfacial Misfit \\
\hline$J_{\mathrm{SC}}$ & Short-Circuit Current Density $\left(\mathrm{A} / \mathrm{cm}^{2}\right)$ \\
\hline LED & Light Emitting Diode \\
\hline LCL & Lateral Conduction Layer \\
\hline LPC & Laser Power Converter \\
\hline MBE & Molecular Beam Epitaxy \\
\hline MEMS & Microelectromechanical systems \\
\hline MIM & Monolithic Interconnected Module \\
\hline MJSC & Multijunction Solar Cell \\
\hline
\end{tabular}




$\begin{array}{ll}\text { MOVPE } & \text { Metal Organic Vapor Phase Epitaxy } \\ \text { PECVD } & \text { Plasma Enhanced Chemical Vapor Deposition } \\ \text { QE } & \text { Photovoltaic } \\ \text { RIE-ICP } & \text { Reactive Ion Etching in Inductively Coupled Plasma } \\ \text { RTG } & \text { Radioisotope Thermoelectric Generator } \\ \text { RTPV } & \text { Radioisotope Thermophotovoltaic } \\ \text { SI } & \text { Semi Insulating } \\ \text { SOE } & \text { Secondary Optical Element } \\ \text { SOI } & \text { Semiconductor On Insulator } \\ \text { TPV } & \text { Thermophotovoltaic } \\ V_{\text {OC }} & \text { Open-Circuit Voltage (V) } \\ \text { WSI } & \text { Wafer Scale Integrated } \\ & \end{array}$




\section{Introduction}

Monolithic Interconnected Modules (MIMs) are densely packed arrays of series interconnected photovoltaic (PV) cells that share the same semiconductor substrate. These devices have been extensively developed during the past few decades for high irradiance PV (HIPV) applications, which are characterized by a significantly high irradiance impinging on the PV converter. The most remarkable examples of HIPVs include concentrator PV (CPV) [1-3], thermophotovoltaics (TPV) [4, 5], and laser-power-conversion (LPC) [6, 7]. In these applications, the PV cell is illuminated by irradiances that typically exceed several tens of W/ $\mathrm{cm}^{2}$, i.e. 100 's times the solar irradiance on Earth. Under these conditions, the PV cells produce extremely high current densities $(J)$, and the fabrication of densely packed arrays of small PV cells becomes necessary in order to reduce (increase) the output current (voltage) of the module.

Several concepts have been developed to manufacture densely packed arrays comprising spare PV cells [8-13], most of them involving a relatively complex assembling technique. MIMs provide an effective alternative to these concepts, enabling a significant reduction of the module area devoted to cell interconnection; and notably simplifying the assembly of the full PV receptor.

In this article we review the historical development of MIMs, providing a compilation of references on this topic and summarizing the different technological options that have been developed during the last four decades. The purposes of this review are to overview and classify the different types of MIMs, to establish the current state of the art, and to identify the most promising future developments.

In section 2, we summarize the main kinds of MIMs, introducing the main concepts related with this technology. Sections 3, 4, 5, and 6 describe the specific developments of MIMs based on Si, GaAs, InP, and GaSb, respectively. Section 7 describes those activities on MIMs comprising III-V based multijunction subcells and finally, section 8 provides a compilation of the most remarkable works along with a description of some possible developments envisaged for the future.

\section{MIM technology overview}

In an attempt to classify the different MIM technologies, in this article we pay attention to three of their main differentiating features: the semiconductor compound, the electrical isolation technique, and the final application.

Attending to the application, we found three main types of MIMs: those used in CPV, TPV or LPC environments. Regarding CPV, MIMs have been developed for dish/tower CPV power 
generation systems, where the sunlight is concentrated by a factor as high as several hundreds on highly efficient, actively cooled PV arrays of relevant size of a few tens of $\mathrm{cm}^{2}$. Dish/towerCPV systems are an alternative to conventional CPV, with the difference of a single concentrated light spot per systems instead of multiple concentrated spots, each of them illuminating individual cells. The large PV receptor area of dish/tower CPVs makes MIMs perfectly suited for this application, to minimize the area of the receptor dedicated to the interconnection between cells. In TPV applications, the diffuse radiant heat originating from an incandescent source is converted into electricity by infrared-sensitive PV cells. In this case, the irradiance strongly depends on the source temperature and emissivity, ranging from $\sim 10 \mathrm{~W} / \mathrm{cm}^{2}$ for $1000{ }^{\circ} \mathrm{C}$ to $\sim 100 \mathrm{~W} / \mathrm{cm}^{2}$ at $2000{ }^{\circ} \mathrm{C}$. Due to the nature of the irradiation, TPV applications are typically extended to large areas, where the use of MIMs enables higher collection efficiency and output voltage. Finally, LPCs makes wireless power transfer from the generator to remote loads possible (e.g. satellites, dangerous environments, etc.) by using a laser power source. LPCs convert laser power into electricity at very high efficiencies (>50\%) and may operate in the broad range from $\sim 1$ to $\sim 200 \mathrm{~W} / \mathrm{cm}^{2}$, depending on the laser power output. In this case, MIMs enable to boost the output voltage avoiding the use of DC/DC converters. Another possible field of application for HIPV MIMs is microelectromechanical systems (MEMS), which require a high voltage DC power supply. In this case, MIMs enable the miniaturization of high voltage, chip-integrated power supplies.

Attending to the semiconductor compound, we find two main categories: the ones based on $\mathrm{Si}$ and the ones based on III-V semiconductor substrates. Si substrates were mostly used during the early times of MIM development technology and they were typically devoted to solar applications. However, the advent of III-V semiconductors in the early 80's rapidly impacted the MIM development and most subsequent works focused on III-V-based devices in order to take advantage of their greater versatility regarding ternary and quaternary alloying and the availability of different substrates. Among the III-V options, only three substrates have been used so far to fabricate MIMs: GaAs, InP, and GaSb. A number of compounds have been grown by molecular beam epitaxy (MBE), metal organic vapor phase epitaxy (MOVPE), and liquid phase epitaxy (LPE), to produce different types of III-V-based MIMs. For instance, GaAs substrates have been used to fabricate (In)GaAs and GaInP devices, suitable for most visible and near-infrared applications, e.g. most CPV and some LPCs. In applications requiring spectral response at longer wavelengths, $\mathrm{InP}$ and $\mathrm{GaSb}$ have been used to grow different kinds of compounds with bandgaps ranging from 0.5 to $0.75 \mathrm{eV}$, such as InGaAsSb on GaSb (used in TPV applications) and InGaAs on InP (widely used in TPV and LPC applications).

Attending to the electrical isolation of MIMs, we find three main categories: those based on semi-insulating (SI) substrates, those using cell-isolation diodes (CID), and those based on 
semiconductor-on-insulator (SOI) substrates. The most robust and simple solution is the use of SI substrates, which are manufactured by incorporating certain defects in the semiconductor lattice that cause the Fermi level to be pinned close to the center of the bandgap, emulating the case of a perfectly intrinsic (highly resistive) semiconductor. In this case, the electrical insulation between subcells is readily accomplished by means of wells etched down to the substrate. These wells are covered by an insulating layer to protect the exposed perimeter area of the subcells, allowing the deposition of metals to series-connect adjacent subcells without short-circuiting (Figure 1). The use of SI substrates is the most common choice for manufacturing MIMs on GaAs and InP substrates, for which commercial SI substrates are readily available. Unfortunately, no high quality SI substrate exists on $\mathrm{Si}$ or GaSb. Thus, they require other strategies such as the integration of CIDs to create a reverse polarity of the substrate with respect to the subcell base that electrically isolate adjacent subcells. One crucial limitation of this design concerns the CID reverse-bias operation: if the CID is illuminated, there will be a current path through the CID that could short-circuit the corresponding subcell. Besides, there is a limit in the number of subcells that can be series-connected corresponding to the CID breakdown voltage. Other works used SOI substrates, which are manufactured by bonding the active semiconductor layers to an insulating holding substrate, such as glass or ceramics. In this case, the electrical isolation is performed similarly to the case of SI substrates. This strategy typically involves some kind of epitaxial lift off (ELO) process to transfer the very thin active epitaxial layers to the final substrate.

\section{Si-based MIMs}

One of the first methods to fabricate Si MIM devices was patented by Riel in 1970 [14] and utilized the CID strategy (Figure 2-a). In order to mitigate the possible short-circuits caused by illuminated CID, their minority carrier lifetime had to be reduced below $10 \mathrm{~ns}$ and they had to use very thick layers, at least twice the diffusion length, as proposed by Chiang et al. in 1979 [15].

In a series of publications dated from 1976 to 1983 [16-21], Warner proposed two alternatives to the designs by Riel and Chiang based on the use of SOI substrates. One of the Warner's designs (Figure 2-b) used doping wells for the lateral isolation of the subcells. For producing these wells by conventional diffusion doping processes it was necessary to polish the Si wafer until reaching a thickness of $\sim 30 \mu \mathrm{m}$. Although still based on CID isolation, in this design, the use of CID was restricted to the adjacent subcells, thus mitigating illuminated CID issues because, under this configuration, they are shadowed by the metallic grid. In 1979, Wada et al. [22] proposed an alternative to Warner's designs in which lateral isolation was carried out by doping from the two sides of the wafer simultaneously. This enabled very deep isolation wells 
and consequently avoided the requirement of very thin wafers on SOI substrates, at the expenses of requiring a more complex photolithographic process. Later on, Warner proposed a simpler approach for selective deep diffusion using an $\mathrm{Al}$ thermomigration technique [18]. In spite of the improvements with respect to the original design by Warner, all the above described designs still require reverse junction electrical isolation, with the associated shunting risks.

A second design proposed by Warner consisted on creating isolation baskets or wide grooves, the so-called etched multiple vertical junction (EMVJ), in which the active device was confined (Figure 2-c). A similar approach was proposed by Kaplow and Frank, in a journal article [23] and in a series of patents dated from 1978 to 1979 [24-27]. This kind of devices were fabricated and tested under concentrated sunlight (300 suns) to reach conversion efficiencies above $19 \%$ [23]. A similar concept was proposed by Chappell [28] (Figure 2-d) except for using substantially different processing steps that involved ionic implantation and anisotropic chemical etching. At the end, solar MIMs were fabricated using this concept, demonstrating efficiencies of $12.2 \%$ under illuminations of 300 suns [28]. In both designs, efficiencies above $20 \%$ were expected after some minor technological improvements.

Similar ideas were proposed by Moddel [29], Sinton [30] and Kurt [31] in 1986, 1992 and 1995 respectively. Moreover, the Company AstroPower Inc. presented from 1993 to 2003 [32-34] results of MIMs for space power applications by using a design with similar characteristics to that of Warner [21], Chapell [28] and Kaplow and Frank [23-27], which demonstrated experimental efficiencies of $11.1 \%$ at 1-sun illumination [33]. In 2003, Peters et al. [35] presented efficiencies of $11 \%$ for MIM devices on SOI substrates using the aforementioned groove-like isolation. In 2005, using a similar design (Figure 2-e), Bermejo [36, 37] and Hammud [38] presented Si MIMs with efficiencies of $4 \%$ and $10.5 \%$, respectively.

Besides the already discussed alternatives using CID and SOI insulation techniques, there are works proposing the use of SI semiconductor substrates. One of the first references is that of Routh et al. [39] from 1979. Routh proposed two alternatives: the use of insulating substrates, such as sapphire or highly resistive $\mathrm{Si}$, where the insulation was achieved by means of wells etched all through the substrate, such as in Figure 2-e. In 1982, Evans et al. [40] proposed a similar design in which a highly resistive Si instead of SOI is used. In this case, grooves do not necessarily have to penetrate all through the semiconductor substrate. The use of highly resistive Si substrates was further developed by Valco, Kapor and Evans [41, 42] using a planar technology arrangement (Figure 2-f). In this case, it was observed that insulation was only effective for concentration levels of at least 5 suns. This is because at such high concentration, the current contribution through the shunt resistances is insignificant. 
In 1982, Green proposed a design that included an integrated bypass diode for each subcell [43]. In this case, the insulation was obtained by relatively large distance and highly resistive semiconductor regions. That same year, Goetzberger [44] proposed an improved insulation scheme by adding grooves to Green's design.

In 1990, Swanson [45, 46] proposed an insulation scheme based on back point contact (BPC) solar cells using shunted $\mathrm{p} / \mathrm{n}$ junctions in the perimeter of each cell as minority carrier traps. The device also included bypass diodes integrated in the structure [45]. A first prototype based on the BPC technology was fabricated using a $6 \times 6 \mathrm{~cm}^{2}$ monolithic PV module that integrates two parallel strings of 5 series-connected BPC, producing $140 \mathrm{~W}$ under an illumination of 200 suns [47]. The so-called wafer scale integrated (WSI) module of BPC cells is designed for central receiver or concentrating dish applications. The record efficiency of this technology measured under standard conditions $\left(25^{\circ} \mathrm{C}\right.$ solar cell temperature) is $22 \%$, obtained at 58 suns. Regarding other implementations of this MIM technology, a $10 \mathrm{~kW}$ reflective dish CPV system was presented by Tilford et al. [48] and co-authored by Swanson and co-workers from SunPower Corporation. The CPV receiver consisted of 10 series/parallel connected cells on a single $\mathrm{Si}$ wafer, mounted on a water-cooled plate working at 250 suns. The CPV system was based on an $8.5 \mathrm{~m}$ focal distance concentrator dish-mirror. The measured system efficiency of a smaller prototype (1/3-scaled of the original) was $13 \%$. However, $16 \%$ system efficiency and $23.5 \%$ module efficiency were expected using smaller $26 \%$ efficient concentrator cells.

In 2000, Fath and Keller [49, 50] combined highly resistive Si with groove-insulation. In [50] they presented an elaborate theoretical analysis on monolithic interconnection using a highly resistive semiconductor substrate. A year later, Kerst et al., from the Technical University of Berlin, presented a practical implementation of a similar double isolation scheme using thinfilm crystalline Si. The experimental prototype consisted of a MIM composed of 20 seriesconnected solar cells fabricated using ion implantation and photolithography processes on a lightly B doped $\left(10^{15} \mathrm{~cm}^{-3}\right)$ SOI-wafer with a $15 \mu \mathrm{m}$ thick active layer [51]. The irradiation with an $\mathrm{AM} 1.5 \mathrm{G}$ spectrum light showed an open-circuit voltage $\left(V_{\mathrm{OC}}\right)$ of $7.5 \mathrm{~V}$ and a $J$ above 17 $\mathrm{mA} / \mathrm{cm}^{2}$.

The Toyota Technological Institute from Japan has recently proposed a 3D interconnection consisting of wiring across vertical sidewalls of Si PV cells. This novel device processing technique combines the so-called photoresist spray coating and the angled exposure $[52,53]$ as an alternative to spin coating for the deposition of photoresist patterns in semiconductor devices. The angled exposure and the photoresist spray coating, conversely to standard normal exposure, allows patterning vertical sidewalls, which in turn increases the device processing versatility and enables the possibility of designing more complex monolithic multiple-cell 
architectures. A number of MIM prototypes with different matrix-like configuration have been fabricated with this technique, reaching relatively high voltages and small rise-up times, suitable for integrated circuit and LPC applications.

Regarding MEMS power supply, where high voltage, rather than high current, power or efficiency are required, several solutions have been proposed based on PV solar cells implemented using MIM architectures. The latter are based on SOI substrates and processed using anisotropic etching of the whole active layer. The research group led by Castañer, from the Technical University of Catalonia, has developed a number of MIM devices intended for powering MEMS. Up to 169 cells with an individual $V_{\mathrm{OC}}$ as high as $660 \mathrm{mV}$ have been monolithically interconnected in a $0.42 \mathrm{~cm}^{2}$ module [54], yielding a $V_{\mathrm{OC}}$ of $103 \mathrm{~V}$. The device is fabricated by means of a photolithographic process that achieves both low surface recombination and high bulk lifetimes. Cell interconnection is carried out through the front side of the wafer, following a design similar to that of Figure 2-e, in which a buried oxide is used to isolate the active layers of the device. In another work from this same group [55] a microbattery is assembled to the module for low power-high voltage implantable applications: they exhibit a $V_{\text {oc }}$ of $99 \mathrm{~V}$ and a power density of $4.8 \mathrm{~mW} / \mathrm{cm}^{2}$ [56].

Keeping track of solar cells applied to MEMS power supply, a process based on SOI substrates has been proposed for the integration of power sources, circuits and MEMS within a single monolithic chip, thus, significantly reducing the size of the device. Bellew et al., from the University of California at Berkeley, explains that such integration comprises four major stages: 1) SOI substrate fabrication, in which two oxidized Si wafers are bonded together and polished from one side to obtain the desired thickness, 2) formation of the isolation trenches by means of nitride lining and polysilicon filling, 3) solar cell and circuit fabrication and, 4) etching and release of the MEMS structures [57]. Thanks to this integrated fabrication process, individual cells with efficiencies above $14 \%$ and high voltage arrays with up to 200 monolithically interconnected solar cells have been manufactured, which produce output voltages above $88 \mathrm{~V}$.

This Si-based MIMs section cannot end without mentioning the alternative that exists with respect to crystalline $\mathrm{Si}$ : micrometric size hydrogenated amorphous $\mathrm{Si}$ (a-Si:H) devices have also been proposed in a multijunction configuration and interconnected within the same crystal [58] as a solution to supply MEMS. a-Si:H cells degrade under normal operation, but especially during the first 48 hours, which is evidenced by a significant efficiency drop. However, the output voltage of the cell is reasonably stable, which is the most important criterion for electrostatic MEMS as the operating current is low. In the work by J.B. Lee et al., an a-Si:H solar cell array formed by triple $\mathrm{p}-\mathrm{i}-\mathrm{n} / \mathrm{p}-\mathrm{i}-\mathrm{n} / \mathrm{p}-\mathrm{i}-\mathrm{n}$ multijunction solar cell (MJSC) connecting 
100 of such structures in a $1 \mathrm{~cm}^{2}$ total device area is proposed in order to produce a $V_{\mathrm{OC}}$ of 150 $\mathrm{V}$.

Special mention is obliged regarding the original work by Gover and Stella in 1972, where a vertical multijunction concept is presented [59] meant to prevent a pronounced reduction of the collection efficiency caused by short minority carrier diffusion lengths. This configuration strictly fulfils the definition of a MIM, although its purpose is different than the ones considered in this work. Further works based on vertical junction concepts implemented by means of stacked wafers [60-62] are hence, out of the scope of this review.

\section{GaAs-based MIMs}

The first work in which III-V materials were used to manufacture MIMs was signed by Borden [63, 64] in 1979, working at Varian Associates (Palo Alto, California). Previous works [14, 15, 19-28, 39] had always employed c-Si substrates and manufacturing processes that could not be extrapolated to III-V materials. This was mainly due to the fact that III-V material processing cannot rely on a native thermal oxide mask as it is the case of the $\mathrm{SiO}_{2}$ used in Si. Besides, impurity diffusion processes take place above $700{ }^{\circ} \mathrm{C}$ in most III-V materials, making them useless once they have been subject to such high processing temperature. In previous works, the fabrication of the p-n junction could be made after photolithography patterning using $\mathrm{SiO}_{2}$ masking during the diffusion processes, which is not an option in III-V technology.

Borden suggested a way to process epitaxial semiconductor devices such as III-V MIMs. These processing techniques were the same as those developed for conventional III-V cells (without monolithic interconnection), allowing the separation of the specific MIM processing steps from the epitaxial growth of the semiconductor structure. This manufacturing process modularity enables the integration of a MIM production line into an existing conventional III-V cell production line. Similarly, advances in the technology of conventional III-V solar cells could be directly incorporated into the MIM technology, both in terms of efficiency and cost. Furthermore, the process proposed by Borden did not include high temperature processing steps that may modify the epitaxial structure and therefore the device active layers remain unaffected during the processing.

The main restriction from the process by Borden is the need to grow the semiconductor structure on a SI substrate. Borden manufactured MIM structures such as the ones shown in Figure 3-a and Figure 4-b, from epitaxial stacks based on AlGaAs on GaAs, creating grooves that penetrated to the SI substrate to achieve electrical isolation. Thereafter, a $\mathrm{SiO}_{2}$ insulating layer was deposited in order to protect the exposed area of the p-n junction, allowing the deposition of a metallization to series-connecting adjacent cells without short-circuiting the 
junction. It should be noted that SI GaAs substrates have better electrical insulating properties than those of SI-Si, e.g. the ones from [39-45, 49, 50].

The results presented by Borden [63] showed lower efficiencies than those obtained for conventional cells with the same semiconductor structure $(\eta=13.8 \%)$. The latter can be attributed to two main reasons, being the high series resistance the most feasible one. This resistance came from a poor contact between the $\mathrm{Au}-\mathrm{Ge} / \mathrm{Au}$ metallization and the p-type semiconductor, but also probably to the fact that the current photogenerated throughout the device had to be laterally transported towards the base in order to be collected, which introduced a highly resistive path. The other reason for the low efficiency is attributed to the large area occupied by the interconnection, which included isolation grooves representing $\sim 20 \%$ of the total area, to be compared to a maximum of $10 \%$ shading factor found on conventional concentrator cells. Regarding the latter, Borden argued that much thinner isolation channels could be produced. However, by that time, the main limitation came from the photolithographic process that defined the insulating $\mathrm{SiO}_{2}$ layers within the channel, because this process does not allow direct contact between the photolithography mask and the bottom of the channel, which leads to a reduction of the spatial resolution of the $\mathrm{SiO}_{2}$ patterns. Borden predicted that such problems would appear when trying to make insulation channels below $50 \mu \mathrm{m}$.

It is worth mentioning that in 1981, Masu et al. [65] proposed a number of alternatives to the process by Borden, trying to avoid short-circuiting risks appearing on the subcell perimeter (where, according to the design by Borden, the p-n junction could be short-circuited due to insulation layer defects). Masu proposed two different solutions aimed to prevent the p-n junction to be exposed on the device perimeter: the use of Schottky-barrier cells and p-n structures where the emitter is extended throughout the whole perimeter (Figure 3-b). To our knowledge, no actual devices have been fabricated so far using this design.

In 1990, McClelland et al., from Kopin Corp., presented experimental results on thin-film GaAs MIM devices that were fabricated using the CLEFT (cleavage of lateral epitaxy for transfer) process $[66,67]$, which is used for mechanical lift-off of very thin semiconductor layers (Figure 5). Epitaxial growth is done selectively by means of a mask that is deposited on the wafer prior to the epitaxial process. Front-side processing is done before the lift-off of the active epitaxial layers. After the separation, the back side is processed and the different subcells are isolated by means of insulation wells that reach the SI substrate. One important advantage of this design is that the back side contact covers the whole surface; which eliminates the necessity of lateral conduction and provides a considerably lower interconnection electrical conductivity. Two MIMs of $16 \mathrm{~cm}^{2}$ and $2 \mathrm{~cm}^{2}$ with 4 and 8 subcells respectively, were developed using the CLEFT process [67]. These structures demonstrated efficiencies of 21.2\% at 1-sun AM1.5G and a very 
good fill factor (FF) of 85\%. In 1991, Spitzer et al. [68] presented MIM devices for LPC applications that used the same CLEFT processing. These devices were optimized for an equivalent sunlight concentration of 320 suns and had cylindrical geometry with 2, 6 and 12 subcells. They were measured under laser illumination and demonstrated efficiencies above 50\%. In 1993, Dingle et al. [69] transferred this technology to the development of light-emitting diodes (LEDs) and fabricated an array of 128 LEDs of 30x $15 \mu \mathrm{m}^{2}$ separated by $60 \mu \mathrm{m}$ (centerto-center) that was transferred to a Si chip.

In what follows, we describe GaAs-based MIM developments based on Borden's original design in three particular device applications: LPC, CPV and MEMS.

\section{a) GaAs MIMs for LPC}

In 1991 Beaumont et al. [70], based on the design by Borden [1], presented GaAs PV converters for use on remote power supply applications. These devices were circular in order to match the approximate shape of the incident laser light (Figure 4-a). The active area was divided into 6 sectors electrically isolated and series-connected following the scheme by Borden. The base photocurrent flowed laterally until it reached the emitter contact of the adjacent subcell, which, similarly to the design by Borden, could lead to important ohmic losses if the base conductivity was not sufficiently high. Therefore, high base doping was required to reduce the resistivity, which in turn caused a diminution in the minority carrier lifetime and an increase of the free carrier absorption. To this end, Beaumont proposed the insertion of an $\mathrm{n}^{+}$layer under the base in order to improve the lateral current conduction without greatly impacting the photon absorption in the conventional n-type lightly doped base (Figure 1 and Figure 3-c). Since then, this layer has been known as "lateral conduction layer" (LCL). In 1996 Fahrenbruch et al. [71], in collaboration with Photonic Power Systems Inc., presented a work similar to the one by Beaumont where an $\mathrm{n}^{+}$-GaAs LCL was employed. Fahrenbruch used "floating bridges" to make the connections, thus avoiding the risk of short-circuits on the subcell perimeter.

Peña and Algora [72-76] from the Technical University of Madrid developed a model to explain the complicated interrelations between different design parameters of a MIM device. The results showed that the most limiting features are: base series resistance (including LCL), perimeter recombination and reflection losses at the isolation grooves. Reducing the area of the device entails less resistive losses in the base, but implies higher optical losses at the isolation grooves and higher perimeter recombination. The efficiency decreases as the number of series-connected sectors and the device area are increased. In these studies, the effect of using a LCL with a higher doping and/or greater thickness was also analyzed [76], leading to an optimum value of $10 \mu \mathrm{m}$ for the sum of both base and LCL thicknesses. A theoretical work on the influence of the 
optical misalignment between a laser light source and the LPC device was also presented in [72, 73], where the trade-off between homogeneity and optical losses caused by ray bundles impinging out of the device were analyzed.

In 2006, Peña and Algora [74, 75] presented experimental results on GaAs MIM devices with a circular geometry of $2 \mathrm{~mm}$ diameter using 4 and 6 series-connected sectors. Efficiencies above $43 \%$ were measured under $810 \mathrm{~nm}$ laser illumination for laser powers of about $0.3 \mathrm{~W}$ (9.5 $\mathrm{W} / \mathrm{cm}^{2}$ ). In [74] the influence of the processing steps on the optoelectronic characteristics is analyzed and two crucial steps are identified: the fabrication of the insulation barriers and the cap-etching. Both are related to the possibility of shunting the base of adjacent sectors, the higher series resistance and the losses associated with the non-uniformity of the incoming illumination. A thorough experimental investigation on the impact of LPC misalignment is carried out in [77] for the evaluation of the passive assembly tolerance of the PV receiver with respect to the incident laser spot. In a subsequent work [78], the same authors developed a refined version of the experimental set-up previously used [77], together with a theoretical model to analyze tolerance requirements of existing MIM LPCs.

In 2002, Krut et al. [79] from Spectrolab Inc. developed a 2-subcell MIM for LPC. In this design (Figure 3-d), an n/p structure is used with an n-type LCL (npn-MIM) similar to that described by Wilt et al. [80] (see "InP-based MIMs" section). This design is aimed at reducing the lateral series resistance of the emitter and the LCL thanks to the high mobility of the electrons. The drawback is the necessity of a tunnel junction in order to connect the p-base with the n-LCL. In [79] Krut presented circular MIM devices of $1.5 \mathrm{~mm}$ in diameter that were tested under $810 \mathrm{~nm}$ laser source with input powers in the range of 0.1 to $1 \mathrm{~W}\left(5.7-57 \mathrm{~W} / \mathrm{cm}^{2}\right)$ to demonstrate conversion efficiencies of $40 \%$ for $25 \mathrm{~W} / \mathrm{cm}^{2}$ laser source.

In 2008, Bett et al. and in 2009, Schubert et al. [81, 82], following the preliminary work by Gover and Stella [59] (see "Si-based MIMs" section) for a MJSC with subcells of the same material, proposed two alternative designs for MIM development: a similar concept to that of Krut [79] (Figure 3-d) with an improved GaInP LCL on top of the emitter, and the monolithic stacking of two GaAs subcells connected by a tunnel junction (Figure 3-e). In this last design, the upper subcell is thinner than the lower one in order to match their currents. In this arrangement, the output voltage will be two times higher than that of an independent GaAs cell. Valdivia et al., from the University of Ottawa has recently proposed a similar MIM design for use under laser illumination that produces output voltages higher than $5 \mathrm{~V}$ [83]. This design comprises up to five monolithic, lattice-matched, vertical stack single-junction GaAs subcells separated by identical tunnel junctions. Such structure resembles a MJSC except that all subcells are made of the same semiconductor material and the photons to be absorbed are 
monochromatic. As in [81, 82], each of these junctions has a variable thickness that is function of the photon flux that it is meant to absorb according to the subcell series-connection photocurrent constraint. The device showed a conversion efficiency of $60.1 \%$ under $835 \mathrm{~nm}$ laser illumination with an equivalent irradiance of 110 suns. Advantageously, the verticallystacked monolithic configuration eliminates the need for fabricating isolating trenches and further metal interconnections. This provides simpler manufacturing process, increased light collection, photogenerated current and insensitivity to the alignment of the incident spot to lateral or angular errors.

\section{b) GaAs MIMs for CPV}

The first reference presenting a MIM device for dish-CPV applications is authored by Ward. et al. [84] in 1998, who directly transferred their previous TPV designs to CPV applications (see "InP-based MIMs" section). In [85] he presented a 4-subcell MIM of $0.25 \mathrm{~cm}^{2}$ using an $\mathrm{n} / \mathrm{p}$ structure with p-type LCL (the same as that of Figure 3-c but using reverse polarity). Although the device was not fully optimized, a high FF of $72 \%$ for 390 suns was demonstrated.

In the framework of the HICON-PV project (2004-2006), van Riesen et al. [86, 87] manufactured a $1 \mathrm{~cm}^{2} \mathrm{GaAs}$ MIM containing 10 subcells using a p/n structure and a $3 \mu \mathrm{m}$ thick n-type LCL. The measured efficiency was $11.5 \%$ at 500 suns. The results revealed series resistance issues caused by the metal contact and shunting due to bad performing perimeter insulation. The use of different polarities for the emitter and the LCL forced to independently optimize the metal contacts for each of these layers, which was not relevant in TPV devices, where low bandgap materials are used. In [86] a Ti/Pd/Au system was used to contact the pGaAs emitter, while a structure with $\mathrm{Ni} / \mathrm{AuGe} / \mathrm{Ni}$ was used to contact the n-type LCL. The perimeter insulation was carried out by means of $600 \mathrm{~nm}$ thick $\mathrm{SiN} / \mathrm{SiO}_{2}$ layers. In subsequent works, this MIM device was further optimized: in [87] the AlGaAs window layer was substituted by GaInP and the insulation was substituted by a polyamide, such as in [75]. The emitter contact was also substituted by a $\mathrm{Cr} / \mathrm{ZnAu}$ system, in addition to a $3 \mu \mathrm{m}$ thick silver layer aimed at improving grid conductivity. Thanks to these improvements, efficiencies of $20.8 \%$ at $150 \mathrm{X}$ and $17 \%$ at $1000 \mathrm{X}$ were measured.

Loeckenhoff et al. [88] proposed a new MIM design based on Wilt's n/p/n design [80] (Figure 3-d) and with an integrated monolithic bypass diode (Figure 3-f). One of the advantages with respect to previous HICON-PV designs was the possibility of using the same metal combination (Ni/AuGe/Ni) for the two LCLs (LCL1 and LCL2 in Figure 3-f) and the emitter (all of them ntype). The drawback of this design is the larger area dedicated to the insulation wells (about 100 $\mu \mathrm{m})$. However, still some issues concerning the metal-semiconductor contact and tunnel 
junction breakdown were detected in these devices. Loeckenhoff solved these problems [89] by changing the metallization from $\mathrm{Ni} / \mathrm{AuGe} / \mathrm{Ni}$ to $\mathrm{Pd} / \mathrm{Ge}$ and improving the growth technique of the tunnel junction layers. Besides, a back surface Ti/Au reflector was incorporated to improve the heat management of the device. In [89] it was finally presented a 24 MIM integration on a $10 \times 10 \mathrm{~cm}^{2}$ receptor (Figure 6). The highest MIM conversion efficiencies were $22 \%$ at $200 \mathrm{X}$ and $19.9 \%$ at $962 \mathrm{X}$. The average efficiency of the 24 MIM devices was $16.7 \%$ and the overall module efficiency containing 24 MIMs (6 in parallel and 4 in series, see Figure 6) was $17 \%$ at $40 \mathrm{X}$ (no results were presented at higher concentrations). It is remarkable the very high $V_{\mathrm{OC}}$ of $110.6 \mathrm{~V}$ if compared with the small short-circuit current of $0.8 \mathrm{~A}$, for a FF of $78 \%$.

References on the integration of MIM devices in complete CPV systems can be found in [90] and [91]. A comparative study of different MIM devices developed within HICON-PV can be found in [92]. In [93] Loeckenhoff summarizes the work done on the fabrication of MIM devices and their integration on a complete CPV receiver. In Ref. [94], a $4.33 \mathrm{~cm}^{2}$ singlejunction GaAs MIM consisting of 23 interconnected cells is attached to a manifold microchannel heat sink meant to recover and make a profitable use of the thermal energy produced. Such combined high concentrator PV and thermal system is known as high concentrated PV thermal (HCPVT). When thermal power is taken into account, the combined efficiency of the system increases from $15 \%$ to $60 \%$. Besides, the performance of the PV part is very little affected by the coolant temperature increase (from $25{ }^{\circ} \mathrm{C}$ to $70{ }^{\circ} \mathrm{C}$ ) required to maximize the exergy efficiency. An equivalent HCPV system was designed including four MIM attached to a secondary optical element (SOE) devoted to increase concentration and homogenization of the irradiance on the cell surface, and the efficiency improved to 63\% [95].

Similar developments have been recently carried out at the University of Tokyo, where the use of monolithically integrated bypass diodes adjacent to each subcell without the need for extra LCL [96] have been investigated, as it was originally proposed by Loeckenhoff [88]. In [97], they presented a $50 \mathrm{~mm}^{2}$ MIM with $5 \mathrm{p} / \mathrm{n}$ subcells and n-type LCL (as in Figure 1 and Figure 3c) that claim improved mesa profiles and better insulating material than the common polyimide used between mesa sidewalls and electrodes from adjacent subcells. On the one hand, abrupt vertical mesas are obtained using $\mathrm{Cl}_{2}$ plasma etching and, on the other hand, performing $\mathrm{SiO}_{2}$ insulating layers deposited by sputtering are used to isolate the MIM segments. A relatively high packed configuration is obtained, with up to $82 \%$ effective useful active area: only $9 \%$ of the whole MIM area is covered by insulator and another $9 \%$ is filled by the metal grid. 1 sun characterization showed MIM efficiencies slightly higher than $15 \%$ and a $V_{\mathrm{OC}}$ close to $1 \mathrm{~V}$ per cell. 


\section{c) GaAs MIMs for MEMS}

The use of GaAs MIMs has also been reported for the application to MEMS. Small GaAs cells on SI substrates present power loss mechanisms related to the leakage current (shunt resistance), rather than series resistance, as it is usually the case in conventional PV solar cells. The use of III-V materials for the implementation of MIM devices present the advantage of SI substrate availability and the possibility for enabling a higher $V_{\mathrm{OC}}$ per cell, i.e. GaAs and related materials have bandgaps that are both greater than that of $\mathrm{Si}$ as well as direct, which allows $\mathrm{q} \cdot V_{\mathrm{OC}}$ closer to the bandgap energy. Furthermore, the III-V solar cell absorption threshold can be easily tuned thanks to the possibility of ternary and quaternary alloying, which is an interesting electronic feature as regards of wavelength selectivity applied to MEMS power supply, i.e. light beams of different wavelengths can be used independently for the activation of the MIM devices.

In [98] a monolithical array with 24 series-connected micro-solar cells is presented for its use in the field of MEMS power supply. The cell array is integrated in a rectangular $0.8 \mathrm{~mm}^{2} \mathrm{MIM}$ device fabricated on a SI GaAs substrate and interconnected on the flip side of the substrate via holes. It shows a $V_{\mathrm{OC}}$ of $22.5 \mathrm{~V}$ under a monochromatic illumination of $815 \mathrm{~nm}$ and an irradiance equivalent to approximately 5 suns. The leakage current, which drives the losses of the device, is measured and modeled, being identified as occurring throughout the illuminated surface of the SI substrate. Metallic light-blocking films were deposited in the vicinity of the cells during the process of wiring lead formation in order to suppress photocurrent in the surface region, which in turn prevents further reduction of the substrate sheet resistance and hence, decreases the leakage current.

In a further work, Ohsawa obtains $100 \mathrm{~V}$ from a MIM containing 120 cells [99] with a similar concept. The response of the device is analyzed as a function of transient light for its use in MEMS with satisfactory results.

A theoretical work by Y. Wang et al. studies the effect of the MIM leakage current and proposes a modification of the conventional solar cell equivalent circuit model consisting of the addition of a shunt resistor on its terminals [100]. Results from this model show that the quality of the MIM fabricated with GaAs cells on SI substrate (mainly the $V_{\mathrm{OC}}$ ) can be significantly improved through the reduction of the number of cells per line and a relative cell area that maximizes the trade-off between leakage current and perimeter recombination (simulations place this optimum between $80 \%$ and $90 \%$ ).

The same research groups later proposed a $1 \mathrm{~cm}^{2}$ experimental implementation with $108 \mathrm{GaAs}$ cells that produce a $V_{\mathrm{OC}}$ of $84 \mathrm{~V}$ using a $\mathrm{SiO}_{2} / \mathrm{TiAu} / \mathrm{SiO}_{2}$ multiple-layer structure in addition to the more common polyimide insulating layer [101]. The MIM provided an efficiency of $11.2 \%$. 
In [102], a cell perimeter to area threshold is set for the GaAs micro-cells used in MEMS MIM from which the recombination in the space charge region is dominated by the perimeter surface.

\section{InP-based MIMs}

InP arises as a promising substrate candidate for low-bandgap semiconductors with direct bandgaps in the range of $\sim 0.55-0.74 \mathrm{eV}$. These low-bandgaps are well suited for TPV, which requires absorbing low energy photons emitted by incandescent bodies. Similarly, a wide family of LPCs employs low-bandgap semiconductors to convert infrared laser light into electric power, matching the transmission windows of fiber optics. Such low-bandgap PV devices could not be readily fabricated on GaAs because no low-bandgap ternary or quaternary alloy exist lattice matched to GaAs and very restricted possibilities exist close to its lattice constant, all of them with bandgap energies very close to $1.4 \mathrm{eV}$. Most of the existing works on MIMs manufactured using InP substrates are based on InGaAs compounds. This ternaries can be grown lattice-matched to InP with a bandgap of $0.74 \mathrm{eV}$ and lattice-mismatched with bandgap energies as low as $0.55 \mathrm{eV}$. Other options employ quaternary compounds such as InAlGaAs or InGaAsP meant to lower the absorption threshold and adapt the lattice constant to that of InP. In what follows, the advances proposed by the different works devoted to LPC and TPV using InPbased substrates are described.

\section{a) InGaAs MIMs for LPC}

The first work in which a monolithic series-connection of cells is carried out using InP substrates was presented by $\mathrm{Ng}$ et al. [103] in 1982. In addition, this is the first reference we can find about MIMs applied to remote LPC. The device consists of a GaInAsP/InP heterostructure divided into 12 subcells arranged in a radial configuration. Once the semiconductor structure has been fabricated, the interconnections are made by "wire-bonding" as Borden did in the past [63] as well as other authors $[65,70,72-76,79,82]$. Ng obtained efficiencies of $\sim 30 \%$ under the illumination of $1.06 \mu \mathrm{m}$ and $44 \mathrm{~mW}$ laser, achieving a FF of $76 \%$.

In 1994, Wojtczuk et al. [104-106], from Spire Corporation, presented PV devices designed to operate with laser light of wavelengths between $1.3 \mu \mathrm{m}$ and $1.5 \mu \mathrm{m}$. This work is the first in which remote LPC were developed in this wavelength range. In [106] results from MIMs based on InGaAs and InAlGaAs (both epitaxially grown on InP) are presented. In both cases, a p-n structure is used with an n-type InGaAs LCL (Figure 3-c). The rationale behind the use of InAlGaAs is the greater versatility to tune the bandgap energy, which in turn, is meant to provide optimized solutions for a given spectrum. However, most results obtained from InGaAs devices were better than the ones obtained from InAlGaAs despite having optimum gap. In 
particular, the quantum efficiency $(\mathrm{QE})$ obtained from the ternary was considerably better, because the epitaxial growth of a quaternary material such as InAlGaAs is more complex and is subject to problems related to material quality, atomic ordering, dislocations, etc. Furthermore, $\mathrm{Al}$ is easily contaminated with oxygen, creating additional recombination centers. InGaAs MIM devices comprising 8 subcells were illuminated by a solar simulator to produce an irradiance of $4.1 \mathrm{~W}\left(5.12 \mathrm{~W} / \mathrm{cm}^{2}\right)$ and $0.45 \mathrm{~W}\left(0.56 \mathrm{~W} / \mathrm{cm}^{2}\right)$. The device showed efficiencies of $16 \%$ $\left(F F=51 \%, V_{\mathrm{OC}}=2.98 \mathrm{~V}\right.$, short-circuit current $\left.\left(I_{\mathrm{SC}}\right)=0.42 \mathrm{~A}\right)$ and $22 \%\left(F F=70 \%, V_{\mathrm{OC}}=3.02 \mathrm{~V}\right.$, $I_{\mathrm{SC}}=46 \mathrm{~mA}$ ) respectively. According to [106], high series resistance losses from different components impacted the device performance (front-grid metallization, LCL, emitter, etc.). Other losses related to the processing of the device were pointed out regarding the definition of the dielectric layers used for the isolation grooves, related to difficulties in the photolithographic process on non-planar surfaces, which may lead to the appearance of short-circuits. In [105], InGaAs MIM devices, both InP lattice-matched (bandgap wavelength of $1.65 \mu \mathrm{m}$ ) and latticemismatched (bandgap wavelength of $2.2 \mu \mathrm{m}$ ) are presented.

It is worth mentioning that Wojtczuc although focused on LPC applications, presented a theoretical analysis [107] of the advantages of the MIM technology applied to TPV, when this community was beginning to be interested in this technology (in particular Wilt et al. [108]).

\section{b) InGaAs MIMs for TPV}

The first reference in which MIMs are used for TPV applications appeared in 1996 and belongs to the joint effort of NASA and Essential Research Inc. (Wilt et al [108]). They combined for the first time two old concepts: Back Surface Reflector (BSR) ${ }^{1}$ and monolithic integration. Both concepts accurately fit with the requirements of a TPV system, in which a photon recirculation system is required and in which the power density of the incoming light is very high. In addition, both the inclusion of BSRs and the monolithic integration shared the need for SI substrates, on the one hand to prevent free electron absorption and on the other hand to ease electrical isolation between subcells. The semiconductor structure used in [108] was p over $n$ $(\mathrm{p} / \mathrm{n})$ in order to include an LCL under the n-type base (Figure 3-c), taking advantage of the greater electron mobility compared to that of holes. Furthermore, the increase in optical bandgap caused by a high InGaAs n-type doping of the LCL (attributable to the Burstein-Moss shift due to degeneracy of the heavily doped $\mathrm{n}^{++}$material) allowed photons with energy slightly above the gap that were not absorbed in the base, not to be absorbed in the LCL, being reflected

\footnotetext{
${ }^{1}$ The incorporation of a reflector on the rear of the cell allows the reflection of photons that are not absorbed by the active semiconductor layers. Such recirculation allows, on the one hand, reducing the requirements for thermal dissipation, and on the other hand, the application of spectral control techniques, returning the unabsorbed photons to the emitter.
} 
in the rear reflector and increasing the probability to be absorbed in the base. This enabled the design of a narrow base without sacrificing photon absorption ${ }^{2}$. A narrow base has three main advantages: increased $V_{\mathrm{OC}}$, enhanced collection probability and ease of the narrow isolation channel processing. Another reason for using a p/n structure was the fact that the free electron absorption is much smaller (3.5 times) in n-InGaAs than in p-InGaAs, so absorption losses caused by free carriers are reduced because of the much thinner emitter layer compared to the base.

The devices presented in [108] consist of 8 subcells of $1.2 \times 10 \mathrm{~mm}^{2}$ each, electrically isolated by an electronic configuration similar to that introduced by Borden [63], where the insulator channel was $270 \mu \mathrm{m}$ wide and used $\mathrm{SiO}_{\mathrm{x}}$ as dielectric insulator. The LCL comprised a thickness of $2.7 \mu \mathrm{m}$. AuGe contacts were used to connect both the p-type emitter and the n-type LCL. This was not possible in higher bandgap materials, such as GaAs (see "GaAs-based MIMs" section), for which metal-semiconductor ohmic contacts are more complicated to obtain. The results showed a $V_{\mathrm{OC}}$ of $0.488 \mathrm{~V}$ and a FF of $40.9 \%$ at 1 sun and a $V_{\mathrm{OC}}$ of $2.6 \mathrm{~V}$ and a FF of $53 \%$ at 140 suns. Parallel resistance problems (related to short-circuits in the perimeter of the subcells) as well as series resistance problems (due to problems with the semiconductor structure, LCL resistivity and the metal contacts) were identified.

During the next two years, Wilt and Fatemi continued the work begun in [108] and presented devices incorporating a number of improvements [109, 110], which are fully described in [111]. Different dielectric materials were tested as insulators: $\mathrm{Ta}_{2} \mathrm{O}_{5}$, spin-on-glass and $\mathrm{Si}_{3} \mathrm{~N}_{4}$, being the latter the one offering best results with resistivities higher than $10^{10} \mathrm{ohm} \cdot \mathrm{cm}$. As to metal contacts, several options were tested looking for a low specific contact resistance, good adhesion both with InGaAs (n- and p-type) as well as with insulating materials and a high reflectivity in the infrared. They identified both $\mathrm{Cr}-\mathrm{Au}$ and $\mathrm{Ti}-\mathrm{Au}$ as good alternatives, although the $\mathrm{Cr}$ layer deteriorated the reflection properties, so the BSR metallization was finally made of $\mathrm{Au}$. These device processing modifications were employed for the manufacture of two types of semiconductor structures, one of which consisted of an InGaAs device lattice-matched to InP, constraining the InGaAs bandgap energy to $0.74 \mathrm{eV}$. The other structure consisted of an InGaAs material lattice-mismatched to InP in order to obtain a bandgap of $0.55 \mathrm{eV}$, more suitable for TPV applications. The first of them showed better performance than the previous work [92], with a short-circuit current density $\left(J_{\mathrm{SC}}\right)=70 \mathrm{~mA} / \mathrm{cm}^{2}, V_{\mathrm{OC}}=3.2 \mathrm{~V}$ and $\mathrm{FF}=66 \%$. Conversely, the $0.55 \mathrm{eV}$ device showed very poor results $\left(J_{\mathrm{SC}}=4.8 \mathrm{~mA} / \mathrm{cm}^{2}, V_{\mathrm{OC}}=0.668 \mathrm{~V}\right.$ and $\left.\mathrm{FF}=54.6 \%\right)$, although no measurements were performed under high concentration.

\footnotetext{
${ }^{2}$ Long wavelength photons are absorbed by deeper layers of the device and could remain unabsorbed if the device is not thick enough. Therefore, rear reflectors allow doubling the optical path of non-absorbed photons in the device, thus increasing the absorption probability.
} 
In [112], Fatemi and Wilt presented new MIM devices, this time with 15 subcells instead of 8, as it had been the case so far. The insulation channel width was reduced from $270 \mu \mathrm{m}$ to $50 \mu \mathrm{m}$ and therefore the packing density was significantly increased. The metallization interconnection design in the channel was also improved, changing the continuous metal layer for another one including a metallization grid, thus avoiding short-circuits and maximizing photon absorption in these regions ${ }^{3}$ (Figure 4-c). $0.74 \mathrm{eV}$ devices showed FF between $70 \%$ and $75 \%$ for $J$ up to 1.5 $\mathrm{A} / \mathrm{cm}^{2}$ and $0.55 \mathrm{eV}$ MIMs reached this time FF between $58 \%{ }^{4}$ and $62 \%$ for $J$ up to $3.6 \mathrm{~A} / \mathrm{cm}^{2}$.

Almost simultaneously with the designs by Wilt, Ward et al. [85], from the National Renewable Energy Laboratory (NREL), presented a new design for MIM that would be eventually patented [113]. In the conventional MIM design by Wilt, narrow subcells had to be fabricated in order to minimize resistive losses in the LCL. A wider subcell design requires increasing the thickness of the LCL to compensate the larger lateral flow of majoritary carriers, which in turn entails further difficulties regarding the processing of the device (insulation channels become thicker) as well as a deterioration of the photon recirculation process (a wide LCL layer implies a greater absorption by free electrons, which prevents the BSR to redirect unabsorbed photons efficiently). In Ward's design [85] both a front emitter and a rear LCL metallization grids are interdigitated (Figure 4-d). This way a thinner and less doped LCL could be used, drastically diminishing the absorption by free electrons. This concept was named "Grid Finger Interconnected" (GFI). GFI-MIMs of $1 \times 1 \mathrm{~cm}^{2}$ containing eight $0.74 \mathrm{eV}$ InGaAs subcells latticematched to InP were fabricated, obtaining satisfactory results: $\mathrm{FF}=72 \%$ and $V_{\mathrm{OC}}=3.62 \mathrm{~V}$ for a $J_{\mathrm{SC}}$ of $0.9 \mathrm{~A} / \mathrm{cm}^{2}$.

Fatemi and Wilt decided to compare experimentally the aforementioned two design alternatives [114]. In this work they developed GFI-MIM devices with a $0.25 \mu \mathrm{m}$ thick LCL and a doping of $10^{18} \mathrm{~cm}^{-3}$ (to be compared to the $1 \mu \mathrm{m}$ thick and $10^{19} \mathrm{~cm}^{-3}$ doped LCL from the conventional design). Results from different kinds of MIM devices were presented in [114]: employing 0.6 $\mathrm{eV}$ InGaAs (lattice-mismatched to InP) according to the conventional and GFI schemes and $0.74 \mathrm{eV}$ (lattice-matched to InP) devices based on the conventional scheme. The results showed slightly better performance for the conventional devices, either in terms of $J, V_{\mathrm{OC}}$, and FF. However, it should be noted that the worse results obtained for the GFI scheme are related, at least in part, to the larger device area $\left(2.54 \times 2.54 \mathrm{~cm}^{2}\right.$ with respect to $1 \mathrm{~cm}^{2}$ of the conventional design).

\footnotetext{
${ }^{3}$ Later on, Ballinger showed that this option implied larger optical losses and therefore, was not adopted in further works.

${ }^{4}$ It is important to note that the photocurrent generated by same illumination conditions is higher in a low bandgap device and the maximum achievable FF decreases as the bandgap energy is further reduced.
} 
In 1998, a series of works analyzed different aspects of the MIM design: Ringel et al. [115] investigated the inclusion of metallic epitaxial layers replacing the LCL to improve the lateral majoritary carrier transport. In addition, these layers played the role of a BSR. Ballinger et al. [116] presented an analysis of the BSR operation within a MIM device based on Monte-Carlo ray-tracing techniques. Several MIM manufacturing recommendations arise from this modeling regarding the reduction of the optical losses and the improvement of the photon recirculation in TPV systems.

A further work by Wilt [80] [117], showed a new MIM device that substantially improved the ones fabricated so far. Previous designs employed $\mathrm{p} / \mathrm{n}$ structures because the base of the cell had to be electrically connected to a highly conductive n-type LCL. Wilt [80] proposed the use of an $\mathrm{n} / \mathrm{p}$ structure because $\mathrm{n}$-InGaAs features a much lower free carrier absorption compared to $\mathrm{p}$ InGaAs and also because $\mathrm{n}$-InGaAs majoritary carrier mobility is 25 times higher than that of $\mathrm{p}$ type InGaAs. The obvious problem is related to the highly resistive p-type LCL that has to be used instead of the more performing $n$-type one that would produce an $n / p / n$ configuration that includes a reverse $\mathrm{p} / \mathrm{n}$ junction preventing the flow of current. Therefore, to connect the $\mathrm{p}$-type base and the $\mathrm{n}^{++}$-LCL Wilt proposed the inclusion of a tunnel junction between them (Figure 3d).

Wilt showed results of $0.55 \mathrm{eV}$ and $0.74 \mathrm{eV}$ InGaAs MIM devices using this new $\mathrm{n} / \mathrm{p} / \mathrm{n}$ configuration and compared them with previous $(\mathrm{p} / \mathrm{n})$ designs. He always used the same LCL, so the observed differences could only be attributable to the use of $n / p$ or $p / n$ stacking. Apart from the better electrical performance of the $n / p / n$ structure, a clear improvement of the reflected component of the light in the rear side of the device (due to the BSR) is observed, which is attributed to the low free carriers absorption in the emitter.

Regarding the improvement of the 0.55 to $0.6 \mathrm{eV}$ devices (lattice-mismatched to InP), Wilt analyzed different alternatives to grow a buffer layer capable of adapting the lattice constant of the InP substrate towards that of the InGaAs semiconductor [118]. The solution finally adopted consisted of using a gradual InAsP layer. This layer could also be used as LCL if a sufficiently high doping was applied.

In parallel, Murray [119] from Emcore Photovoltaics, developed several devices based on 0.55 $\mathrm{eV}$ InGaAs using the aforementioned $\mathrm{n} / \mathrm{p} / \mathrm{n}$ configuration with a tunnel junction, but using a slightly different epitaxial structure, very similar to the one previously presented by Wanlass (NREL) [120]. It was based on an InAsP/InGaAs double heterostructure (DH) used to reduce minority carrier recombination and including a "step-graded" InAsP layer. As regards of the MIM, the most relevant feature from the design by Wanlass was the use of CID to isolate the cells, which was placed under the DH cell. The CID had a doped $\mathrm{n}^{+} / \mathrm{p}$ ( since the cell was $\mathrm{p} / \mathrm{n}$ ). 
The $\mathrm{n}^{+}$region of the CID was used as stop-etching layer so that the insulation channels penetrated precisely until the $\mathrm{n}^{+}$layer, making possible its use as LCL.

In 2008, J. G. Cederberg, from Sandia National Laboratories presented an InAsP step-graded buffer aimed at growing metamorphic $\mathrm{In}_{0.68} \mathrm{Ga}_{0.32} \mathrm{As}$ cells in MIM configuration on an InP substrate [121]. He addressed the problem of surface defects acting as shunts by modifying pregrowth conditions and produced TPV cells with a $V_{\mathrm{OC}}$ of $348 \mathrm{mV}$ per junction and FF exceeding $70 \%$.

More recently, the team led by S. A. Ringel, from the Ohio State University, developed a metamorphic growth procedure of $\operatorname{In}_{0.69} \mathrm{Ga}_{0.31}$ As cells on SI InP by molecular beam epitaxy (MBE) [122], including a novel $\operatorname{In}_{0.7} \mathrm{Al}_{0.3} \mathrm{As}$ window layer optimized for an $\mathrm{n}$-on-p configuration that incorporates an n-type InAs $\sin _{0.32} \mathrm{P}_{0.68}$ LCL. MIM structures were designed and individual TPV cells were fabricated and measured, achieving a $V$ oc of $0.355 \mathrm{~V}$ and a FF of $66.5 \%$. Outstanding internal QE results for short wavelengths revealed the relevance of the $\operatorname{In}_{0.7} \mathrm{Al}_{0.3} \mathrm{As}$ window layer.

A comprehensive review of InP-based MIMs for TPV applications is presented by Wilt et al. [123]. In [124] a summary of the specific activity of the NREL until 2004 on the manufacture of low-bandgap InGaAs cells on SI InP substrates can be found, including the fabrication of MIMs. From this time on, no new ideas were proposed regarding the single junction MIMs and all the works aimed at the technology transfer to the industry (mainly made by Emcore Photovoltaics) or its application to complete systems. The newest contributions focused on integrating tandem cells in MIM devices. These studies are discussed in the "Multijunction MIMs" section.

In 2004, Wernsman (from Bechtel Bettis Inc.) in collaboration with Emcore Photovoltaics (among others) used $0.6 \mathrm{eV}$ InGaAs MIM devices $\left(2 \times 2 \mathrm{~cm}^{2}\right.$ and 30 subcells) in TPV systems, achieving one of the highest TPV efficiencies to date (close to 24\%) [125].

Emcore Photovoltaics decided to study the feasibility of making $0.6 \mathrm{eV}$ InGaAs MIMs at large scale [126]. The design employed is identical to the previous one presented by Murray [119], which combined the $\mathrm{n} / \mathrm{p} / \mathrm{n}$ design introduced by Wilt [80] and the epitaxial growth based on InAsP/InGaAs DH by Wanlass [120]. They fabricated MIM devices based on three different design variations using a total of $130600 \mu \mathrm{m}$ thick wafers of $76 \mathrm{~mm}$ in diameter, purchased to different suppliers. The whole processing required four different photolithography masks, corresponding to the metallization of the rear contact, etching of the isolation channels, definition of the dielectric layers (insulation and anti-reflecting coating) and front-grid metallization. In [126] a detailed description of the fabrication process as well as the equipment 
employed is presented, together with results on the emitter contact and LCL resistances. Conversion efficiencies of complete TPV systems employing such devices are also shown in reference [127]. In [128] S.L. Murray (also from Emcore Photovoltaics) presented a study on the device metallization regarding the trade-off between electrical and optical operation.

In 2006, Newman, also from Emcore Photovoltaics, presented a joint study with Bechtel Bettis Inc. and Lockheed Martin Corp. in which the yield of a pilot plant devoted to the manufacture of InP substrates-based MIM devices is analyzed [129]. For this purpose, they produced $0.6 \mathrm{eV}$ InGaAs cells on 166 3-inches SI-InP wafers. Different growth and device manufacturing alternatives are also discussed in this work. 36 MIM devices were fabricated on 9 wafers (each containing $42 \times 2 \mathrm{~cm}^{2}$ MIMs) with the following average values: $V_{\mathrm{OC}}=10.93 \mathrm{~V}( \pm 0.023 \mathrm{~V})$ and $\mathrm{FF}=68.3 \%( \pm 0.783 \%)$ for $J_{\mathrm{SC}}=2.23 \mathrm{~A} / \mathrm{cm}^{2}\left( \pm 0.002 \mathrm{~A} / \mathrm{cm}^{2}\right)$. A TPV system average efficiency (defined for a $1000{ }^{\circ} \mathrm{C}$ black body) of $20.3 \%( \pm 0.27 \%)$ is obtained from a sample population of 664 MIMs. In 2007, Su et al. [130], from the University of Notre Dame in the U.S., together with Essential Research Inc. and NASA, showed a numerical modeling of the $0.6 \mathrm{eV}$ InGaAs devices manufactured by Emcore Photovoltaics on SI-InP.

InGaAs TPV MIMs were used by NASA during the development of Radioisotope TPV (RTPV) generators since 2003 [131]. RTPV generators are under development at NASA as a high efficient and high specific-power alternative to current state of the art radioisotope thermoelectric generators (RTGs). State of the art multi-mission RTGs produce $125 \mathrm{~W}_{\mathrm{e}}$ from a total thermal power of $2 \mathrm{~kW}_{\text {th }}$ (efficiency of 6.2\%) which is generated by eight GPHS (general purpose heating system) units containing Pu-238 fuel. RTPV is aimed at producing the same amount of power using only 2 GPHS units, enabling a 5-fold higher specific power of $\sim 15$ $\mathrm{W} / \mathrm{kg}$. The RTPV generator developed by NASA used $0.6 \mathrm{eV}$ InGaAs MIMs produced by Emcore and interference/plasma filters produced by Rugate. A 10x10 $\mathrm{cm}^{2}$ TPV array (Figure 6) containing 16 MIMs, each of them comprising 25 series-interconnected InGaAs subcells, was fabricated to provide $\sim 50 \mathrm{~W}_{\mathrm{e}}$ from a heat source temperature of $1077^{\circ} \mathrm{C}$ (electrically heated), demonstrating conversion efficiencies in the range of $18-20 \%$. Furthermore, neutron radiation tests were carried out to predict a $20 \%$ degradation of the TPV MIM converter by the end of a 14-year mission, which compares to $14 \%$ for the multi-mission RTG system. Furthermore, tests of MIM devices at $90{ }^{\circ} \mathrm{C}$ demonstrated no degradation for 4000 hours of operation.

\section{GaSb-based MIMs}

GaSb-based MIM devices have been developed almost exclusively for TPV applications. The benefit of GaSb for TPV relies on the wide range of available semiconductors lattice-matched to $\mathrm{GaSb}$ with bandgaps ranging from $\sim 0.3 \mathrm{eV}$ to $\sim 1.6 \mathrm{eV}$. As such, it is possible to grow low 
bandgap GaSb-lattice matched ternary and quaternary compounds such as InGaSb, InAsSbP, InAsSb or InGaAsSb, as well as wide-bandgap materials such as $\mathrm{AlGaAsSb}$ or $\mathrm{GaSb}$ for the window layers. Furthermore, by using these materials it is also feasible to manufacture tandem and multijunction TPV cell structures. Unfortunately, the drawback associated with GaSb-based MIM is the lack of GaSb SI-substrates, because of the unavoidable high p-type doping inherent to GaSb. Therefore, the proposed solutions employ other ways of electrical insulation.

One of the alternatives is the use of CID isolation, i.e. reverse p-n junction isolation, as the one patented by Wanlass in [132] and used by Wherer in [133] (see "GaAs-based MIMs" section). This way, the isolation diodes require withstanding the reverse voltage of the whole subcell array that constitutes the MIM, so it is essential that such diodes comprise a high reverse breakdown voltage. Palmisiano et al. [134] from Bechtel Bettis, fabricated InGaAsSb MIMs using AlGaAsSb CIDs with breakdown voltages of 5-7 V. Nevertheless, the resulting 15 seriesconnected cell MIM devices showed a much degraded output voltage of $0.42 \mathrm{~V}$, given that each cell adds approximately $0.2 \mathrm{~V}$. This poor performance was attributed to insulation problems associated to the series-connection of a large number of subcells within the MIM.

Another alternative for manufacturing MIM devices on GaSb wafers is the transfer of the epitaxial layers into an insulating substrate or a substrate coated with insulating layers (e.g. SOI substrate). Under this approach, the substrate could be further coated with a highly reflective coating playing the role of a back surface reflector, which is relevant for spectral control in TPV applications. In [135-138] Wang, from the Massachusetts Institute of Technology, presented InGaAsSb MIM devices on $\mathrm{SiO}_{\mathrm{x}} / \mathrm{Ti} / \mathrm{Au}$ coated GaAs substrates. In this case, the additions of complete subcell voltages within the MIM were demonstrated, i.e. $1.8 \mathrm{~V}$ for a 10 subcell MIM, provided that each subcell produces $\sim 0.2 \mathrm{~V}$ separately. Anyway, the devices manufactured still required an optimization process to reduce ohmic losses throughout the device.

Very recently, MTPV Corp. and collaborators are exploring the possibility of growing epitaxial $\mathrm{GaSb}$ layers on SI-GaAs substrates to manufacture MIM devices [139-141]. These investigations could open the path for manufacturing a number of low bandgap Sb-based MIM devices using the conventional techniques already developed for (In)GaAs compounds, which have already been proved feasible even for industrial scale production.

\section{Multijunction MIMs}

In the early $80 \mathrm{~s}$, Borden, who had already introduced a way to monolithically interconnect GaAs cells in series [63, 64], proposed an alternative to tunnel junctions for use in MJSC architectures. It consisted of etched channels that penetrated to the device regions where the contact was to be made $[142,143]$. This processing technique was proposed as a solution to the 
inefficient tunnel junctions that were fabricated at that time for the series-interconnection of subcells within a MJSC.

Eventually, high quality tunnel junctions were finally achieved and these etched channels were discarded. Anyway, in further MJSC designs, device architectures similar to the one proposed by Borden were employed in order to enable independent access to the terminals of each subcell. This is the case of the design by Wanlass [144, 145], from NREL, who proposed a 3terminal solar cell in tandem configuration using this technique. This design allowed the independent external connection of each cell within the tandem device in different arrays, hence avoiding subcell current-matching.

The integration of a MJSC architecture in a MIM device (MJSC-MIM) was firstly proposed by Spectrolab [146] in which the use of CID insulation is proposed in order to isolate the substrate, generally made of $\mathrm{Ge}$, so that GaInP/GaAs/Ge triple-junctions could be implemented in MIM configuration. To our knowledge, no experimental results of such devices have been presented so far.

\section{a) MJSC-MIMs for TPV}

In 2002, Wherer and Wanlass [133] respectively from Bechtel Bettis Inc. and NREL, in collaboration with NASA and Emcore, started the development of MIM devices for TPV applications. These devices incorporated a tandem configuration with InGaAs subcells latticematched to InP (of $0.74 \mathrm{eV}$ ) and another lower bandgap InGaAs cell (of $0.55 \mathrm{eV}$ ) with a considerable lattice-mismatch with respect to the InP substrate. The interconnection between subcells is performed in a biaxial arrangement, connecting the $0.74 \mathrm{eV}$ InGaAs top-cells and the $0.55 \mathrm{eV}$ InGaAs bottom cells in independent strings. The biaxial connection implies that in each of the directions of the wafer plane $(x, y)$, only one type of subcell is connected (top or bottom), thus creating two independent arrays with four output terminals: two for the top-cell array and another two for the bottom-cell array. This way, the output voltage can be tuned by simply choosing an appropriate number of series-connected subcells in both arrays in order to externally connect them in parallel, which require the same voltage per branch. This interconnection scheme by Wanlass was patented in [147].

In the configuration proposed by Wherer [133], the fabrication of the epitaxial structure requires that the lattice-matched $0.74 \mathrm{eV}$ subcell is grown prior to the buffer layers meant to adapt the lattice constant of the crystal to the $0.55 \mathrm{eV}$ subcell. Such scheme requires the use of an inverted structure, i.e. the radiation first impinges the InP SI substrate. This is possible because the SIInP is transparent to the wavelengths of interest in this case. Each cell consists of a tandem DH 
adopted from the previous work by Wanlass [120]. Another particularity of this design is that an electrical insulator is required in order to interconnect top-cell and bottom-cell independently. For that purpose, in [133] the authors employ a CID adopted from the previous design by Wanlass [120, 132]. The electrical isolation strategy based on a CID consists of an $\mathrm{n} / \mathrm{p} / \mathrm{n}$ structure (where the p-region is lightly doped and the n-regions have a relatively high doping) that prevents current leakages from the subcells of a tandem structure. Furthermore, the n-region from the CID is used to make subcell series-connection (of the same type) within the MIM, since they are in electrical contact with the LCL (also of n-type) of each subcell from the tandem.

The results presented in [133] show a FF of $50 \%$ (and a $J_{\mathrm{SC}}=0.7 \mathrm{~A} / \mathrm{cm}^{2}$ ) for the $0.55 \mathrm{eV}$ cells and a $\mathrm{FF}$ of $65 \%$ (and a $J_{\mathrm{SC}}=0.2 \mathrm{~A} / \mathrm{cm}^{2}$ ) for the $0.75 \mathrm{eV}$ cells. The isolation provided by the diode was sufficiently good, achieving leakage currents below $2 \mathrm{~mA} / \mathrm{cm}^{2}$ for voltages comprised between $-6.2 \mathrm{~V}$ and $8.8 \mathrm{~V}$.

In the following work published by Wherer [148], substantial changes were made with respect to the first design. In the original design, each subcell had to be electrically isolated from each other within each tandem device (by means of CID) in order to connect them externally according to the aforementioned biaxial scheme. However, under this new strategy, both top and bottom subcells are series-connected through a tunnel junction, as it is the case in conventional MJSC. The latter requires that both subcells generate the same photocurrent for a given spectrum, which adds an important constraint to the cell design. Regarding TPV applications, an optimal bandgap configuration for a blackbody radiation spectrum at $1000{ }^{\circ} \mathrm{C}$ was identified as $0.74 \mathrm{eV} / 0.63 \mathrm{eV}$. The $0.74 \mathrm{eV}$ value is imposed by the fact that a particular stoichiometry for the $\operatorname{In}_{x} \mathrm{Ga}_{1-\mathrm{x}} \mathrm{As}$ alloy has to be chosen so that it lattice-matches the InP substrate used for the epitaxial growth of the stack. This tunnel junction strategy replaces the biaxial interconnection scheme by the series-connection of tandem cells. To do this, the "classic" scheme proposed by Wilt [108] is employed, in which the isolation channels penetrate to the SI-InP substrate. Furthermore, Wherer keeps the inverted configuration proposed in his initial design, which reports an important advantage that consists of the possibility of metalizing completely the rear side of the device, thus avoiding lateral conduction of current within the semiconductor. This configuration (Figure 3-g) allows the use of an $\mathrm{n} / \mathrm{p}$ scheme (for each subcell) with just one $\mathrm{n}$ type LCL on top of the n-type emitter of the top-cell, which eliminates the need of extra tunnel junctions typically needed for npn-MIM configuration presented in [80] (Figure 3-d).

The new results obtained by Wherer were significantly better than the ones obtained with his original design for independent tandem cells: $V_{\mathrm{OC}}=0.69 \mathrm{~V}$ and $F F=70.2 \%$ (for $J_{\mathrm{SC}}=0.284 \mathrm{~A} / \mathrm{cm}^{2}$ ) and for the whole MIM consisting of 10 series-connected tandem cells: $V_{\mathrm{OC}}=6.14 \mathrm{~V}$ and 
$F F=67.6 \%$ (for $J_{\mathrm{SC}}=0.282 \mathrm{~A} / \mathrm{cm}^{2}$ ). The $V_{\mathrm{OC}}$ of the whole MIM was lower than expected, which was attributed to isolation problems between MIM subcells.

During 2004, several works were published based on Wherer's concept and focused on different technological features: Wherer himself [149] kept working on the fabrication and optimization of the $0.52 \mathrm{eV}$ InGaAs subcell of the MIM. Wilt [150] studied the influence of including buffer layers within the tandem structure in the performance of the $0,74 \mathrm{eV}$ top subcell. Wanlass and Albin [151] presented a theoretical circuit analysis of double-junction MIM devices.

It is worth mentioning the work by Siergiej [152], also from Bechtel Bettis, who developed, in collaboration with Essential Research a tandem cell on InP based on a new architecture, which included a $0.72 \mathrm{eV}$ InGaAsP junction replacing the $0.74 \mathrm{eV}$ InGaAs one proposed by Wherer. However, no MIM devices were fabricated using this tandem architecture. InGaAsP is latticematched to the $0.6 \mathrm{eV}$ InGaAs bottom subcell and lattice-mismatched to the InP substrate. Thus, under this new scheme, the layer ordering during the growth is altered (Figure 3-h): first the buffer layers are grown to make the transition of lattice constants from InP to the InGaAs ternary corresponding to $0.6 \mathrm{eV}$, then, the $0.6 \mathrm{eV}$ InGaAs is grown and finally, the $0.72 \mathrm{eV}$ InGaAsP lattice-matched junction is grown. With this scheme no buffer layers are included between top and bottom junctions. Moreover, this way, an inverted configuration is not required as the light directly impinges the epitaxial side $^{5}$. Avoiding inverted design implies, on the one hand, that the use of a front grid metallization is again necessary and on the other hand that a tunnel junction is required to electrically connect the p-type base of the bottom junction and the n-type LCL. In this regard, this design takes advantage of the relatively high conductivity of the InPAs buffer layers to use them as LCL. In [152] the electrical and optical properties of these devices are analyzed in order to optimize their structure.

In 2006, Newman [153] from Emcore Photovoltaics, in collaboration with Bechtel Bettis Inc. kept developing the scheme by Siergiej [152] (Figure 3-h). He proposed the use of $0.72 \mathrm{eV}$ AlGaInAs, instead of InGaAsP, to fabricate the top junction. They fabricated three versions of $2 \times 2 \mathrm{~cm}^{2}$ single-junction MIM composed of 30 cells: one with $0.6 \mathrm{eV}$ InGaAs cells, another one using $0.72 \mathrm{eV}$ InGaAsP and a third one employing $0.72 \mathrm{eV}$ AlGaInAs. Very satisfactory $V_{\mathrm{OC}}$ values were obtained, including $14.4 \mathrm{~V}$ for the two $0.72 \mathrm{eV}$ cells. All FF values were higher than $70 \%$. After that, they incorporated these structures in a double-junction MIM with 30 series-connected tandem cells. The InGaAsP/InGaAs MIM produced a $V_{\mathrm{OC}}$ of $24.9 \mathrm{~V}$ with a FF of $68.5 \%$ (for $J_{\mathrm{SC}}=30.75 \mathrm{~mA} / \mathrm{cm}^{2}$ ) and in the case of AlGaInAs $/ \mathrm{InGaAs}$, the $V_{\mathrm{OC}}$ achieved surpassed $25 \mathrm{~V}$ and the $\mathrm{FF}$ was $67.6 \%$ (for $J_{\mathrm{SC}}=32.25 \mathrm{~mA} / \mathrm{cm}^{2}$ ).

\footnotetext{
${ }^{5}$ Actually, the design presented by Siergiej does not impose any constraint regarding the use of an upright or inverted configuration, since the layer ordering of the epitaxial growth could be easily modified so that the $0.6 \mathrm{eV} \mathrm{InGaAs} \mathrm{junction} \mathrm{is} \mathrm{grown} \mathrm{at} \mathrm{the} \mathrm{end,} \mathrm{enabling} \mathrm{the} \mathrm{use} \mathrm{of} \mathrm{an} \mathrm{inverted} \mathrm{structure.}$
} 


\section{b) MJSC-MIMs for CPV}

Previous works devoted to MIM for CPV applications agreed in the necessity of moving to MJSC to further boost the efficiency. The optimum bandgap distribution of double-junction cells adapted to AM1.5D spectrum is close to the $1.4 \mathrm{eV}$ and $1.85 \mathrm{eV}$. These bandgaps are typically obtained using $\mathrm{Ga}(\mathrm{In}) \mathrm{As}$ and GaInP materials lattice-matched to GaAs. In 2010, Helmers, from Fraunhofer ISE, designed and developed a first prototype of dual-junction MIM for its use in large concentrator dish reflector systems working at 1,000 suns $[154,155]$. The works deal with the design and performance of two MJSC epitaxial growth strategies: the lattice-matched approach and the metamorphic one with $\mathrm{Ga}_{0.35} \operatorname{In}_{0.65} \mathrm{P}$ and $\mathrm{Ga}_{0.83} \operatorname{In}_{0.17} \mathrm{As}$ subcell materials, both on SI GaAs. The MJSC MIM follows the integrated bypass diode design by Loeckenhoff [88] (Figure 2-f), except for incorporating a dual-junction device instead of a single-gap cell. Under this approach, two LCL are used together with three different tunnel junctions. In this case, the LCL1 includes a graded buffer that accommodates the lattice constant, absorbing most of the strain generated during the growth of the metamorphic layers.

Different processing techniques applied to semiconductor layer etching and device isolation were implemented and compared with the aim of reducing the interconnection trench width, which in turn minimizes shading losses. An ortophosphoric-based wet chemical etching with the advantages of stopping at designated layers, high throughput and cheap processing was compared to a non-selective reactive ion etching in inductively coupled plasma (RIE-ICP), which obtained accurate structuring, undercut suppression and definable profiles. Device isolation techniques were also compared: on the one hand, a photo-definable polyimide, allowing easy structuring process and improvement of long-term device stabilization, and on the other hand $\mathrm{SiN}_{\mathrm{x}}$ layers applied by plasma-enhanced chemical vapor deposition (PECVD) even at vertical sidewalls and beneath overhangs, which combined with RIE-ICP, allows higher structuring accuracy and hence, an effective reduction of the safety margins. All this progress in advanced processing techniques adapted to MIM manufacturing enabled a reduction of the nominal interconnection trench widths from $100 \mu \mathrm{m}$ to $53 \mu \mathrm{m}$, which in turn reduced shading losses from $10.9 \%$ to $5.7 \%$ and obtained an efficiency of $26 \%$ at an illumination of 500 suns.

In recent times, K. Watanabe, from the University of Tokyo, presented a MIM concept similar to the one reported in [97] except for the use of GaInP/GaAs dual-junction solar cells instead of the previous GaAs single-junction structures. A poor performance was achieved by the 10-cell MIM, which was attributed to the existence of current leakage paths between subcells [156]. 


\section{Compilation and future developments}

During the last few decades, the MIM technology has reached a high level of development, demonstrating in some cases the feasibility of industrial manufacturing. Table 1 compiles electrical data together with the corresponding information on MIM structure, isolation strategy, substrate used, application, type of illumination regarding most relevant MIM structures that have been fabricated and published to date. Only actual experimental results and not the product from modeling or theoretical projection are shown in the table.

Despite the high level of development of MIM technology, there are still a number of PV cell designs that have not been implemented in MIM arrangements (e.g. triple or quadruple junction solar cells) or that have not led to satisfactory results yet (Sb-based MIMs). These kinds of devices are not readily fabricated into a MIM configuration, mainly because their active semiconductor layers are not easily grown on the existing SI substrates (GaAs and InP). Thus, the fabrication of MIMs out of these cell structures require further technological developments, either concerning the use of SOI substrates, ELO techniques or processes that enable the combination of semiconductors with dissimilar lattice constants, such as the use of buffer layers or wafer bonding techniques.

Of particular relevance is the case of triple junction solar cells, which are mandatory to make MIMs competitive in CPV applications. Some possible future triple-junction MIM designs may keep the current state-of-the-art Ge/InGaAs/GaInP cell structure by using Ge-on-Insulator (GOI) substrates [157] or growing epitaxial Ge layers on SI GaAs substrates [158]. Other options are based on SI-GaAs and require the growth of $\sim 1 \mathrm{eV}$ materials, such as GaInNAsSb [159] or strain balanced (SB) quantum nanostructures [160]. Among the options concerning the use of SI substrates, it is also worth mentioning the possibility of fabricating MJSC on SI-InP substrates [161]. Apart of the aforementioned alternatives based on SI substrates, it is also eventually possible to use the inverted metamorphic (IMM) configuration [162] combined with ELO techniques to transfer the active epitaxial layers of a GaAs-based multijunction cell to an insulating substrate. Also, the wafer bonding of GaAs and InP may lead to the fabrication of multijunction cell structures on SI substrates [163].

Another field susceptible of future developments is the Sb-based MIMs, which have not led to satisfactory results yet. These devices are needed in the field of TPV, especially for low temperature applications requiring very low bandgaps (below $0.6 \mathrm{eV}$ ) that are not readily manufactured with InGaAs-on-InP compounds. Recent works on the direct growth of GaSb layers on GaAs include the use of buffer layers [139-141] and interfacial misfit (IMF) arrays [164-167]. Other future developments might be based on different kinds of wafer bonding and ELO techniques $[168,169]$. 
Finally, it is worth mentioning the recent advancements on the many possibilities of manufacturing of III/V semiconductors on Si substrates [170-172]. The progress in this field may enable the drastic reduction of the cost of PV devices based on III-V compounds, including MIMs.

\section{Conclusions}

In this article we have presented a thorough review of the historical development of MIM technology for HIPV applications, establishing the current state of the art and identifying the pending developments for the future. The different kinds of MIM designs that have been developed so far are described, summarized, and classified attending to the semiconductor material, the electrical isolation technique, and the final application. This provides a comprehensive overview of the most promising technological options, along with an insight in the possible future developments.

The review includes a brief description of the Si-based MIMs, which were mainly investigated during the early stages of MIM development, and focused mostly on solar applications. Since the early 80 's most of the research activities moved to III-V semiconductors, either for CPV, LPC and TPV applications. Most remarkable results in this field have been obtained for devices grown on SI GaAs and InP substrates. The former leading to the fabrication of GaAs LPCs and (In)GaAs/GaInP dual junction solar cells; the latter enabling the fabrication of $0.55-0.74 \mathrm{eV}$ InGaAs based MIMs, both single and dual junction and devoted to LPC as well as to TPV applications. Other devices based on the (more challenging) CID and SOI isolation approaches have been also developed, demonstrating good performance.

All these achievements have moved MIM technology to a high level of development, in some cases even demonstrating the feasibility of industrial production. Future developments are still needed to implement some kinds of PV cell structures on MIM arrangements, especially concerning triple and quadruple junction MIMs and high efficient Sb-based TPV cells. The future MIM development may eventually take advantage of the recent advancements in the fields of buffer layers growth, ELO techniques and novel SOI substrates that may enable the fabrication of MIMs on a greater number of semiconductor compounds.

\section{Acknowledgements}

This work has been partially supported by the Project ENE2013-49429-EXP funded by the Spanish National Programmes Ministerio de Economía y Competitividad. 


\section{References}

[1] A. Luque and V. M. Andreev, Concentrator Photovoltaics. Berlin: Springer, 2007.

[2] P. Pérez-Higueras, E. Muñoz, G. Almonacid, and P. G. Vidal, "High Concentrator PhotoVoltaics efficiencies: Present status and forecast," Renewable and Sustainable Energy Reviews, vol. 15, pp. 1810-1815, 2011.

[3] C. Algora and I. Rey-Stolle, Handbook on Concentrator Photovoltaic Technology: Wiley.

[4] T. Bauer, Thermophotovoltaics. Basic Principles and Critical Aspects of System Design. Berlin: Springer, 2011.

[5] D. L. Chubb, Fundamentals of thermophotovoltaic energy conversion: Elsevier, 2007.

[6] L. Summerer and O. Purcell, "Concepts for wireless energy transmission via laser," Europeans Space Agency (ESA)-Advanced Concepts Team, 2009.

[7] M. P. Kazmierkowski and A. J. Moradewicz, "Unplugged But Connected: Review of Contactless Energy Transfer Systems," IEEE Industrial Electronics Magazine, vol. 6, pp. 47-55, 2012.

[8] L. M. Fraas, W. E. Daniels, J. E. Avery, J. E. Samaras, and J. B. Keyes, "Shingle circuits for thermophotovoltaic systems," J. C. Inc., Ed. USA: Shingle circuits for thermophotovoltaic systems, 2001.

[9] H. Hayden, P. Thomas, N. Fette, Z. Farkas, M. Bading, B. Stone, M. Miner, O. Stickroth, $\mathrm{N}$. Bagewadi, and M. Romero, "CPV semi-dense array design for dish and tower collectors," in SPIE Solar Energy+ Technology, pp. 84680I-84680I-14.

[10] G. S. Kinsey, R. A. Sherif, H. L. Cotal, P. Pien, R. R. King, R. J. Brandt, W. G. Wise, E. L. Labios, K. F. Wan, M. Haddad, J. M. Lacey, C. M. Fetzer, P. Verlinden, J. Lasich, and N. H. Karam, "Multijunction Solar Cells for Dense-Array Concentrators," in 2006 IEEE 4th World Conference on Photovoltaic Energy Conference, 2006, pp. 625-627.

[11] A. Salemi, M. Eccher, A. Miotello, and R. S. Brusa, "Dense array connections for photovoltaic systems in concentration," Progress in Photovoltaics: Research and applications, vol. 19, pp. 379-390, 2011.

[12] F.-L. Siaw and K.-K. Chong, "A Systematic Method of Interconnection Optimization for Dense-Array Concentrator Photovoltaic System," The Scientific World Journal, vol. 2013, p. 11, 2013.

[13] F.-L. Siaw, K.-K. Chong, and C.-W. Wong, "A comprehensive study of dense-array concentrator photovoltaic system using non-imaging planar concentrator," Renewable Energy, vol. 62, pp. 542-555, 2014.

[14] R. K. Riel, "Integrated high voltage solar cell panel," Westinghouse Electric Corporation, Pittsburgh, Pa., 1970.

[15] S. Y. Chiang and B. G. Carbajal, "Integrated solar cell array," Texas Instrument Incorporated, Dallas, Tex., 1979.

[16] E. M. Murray and R. M. Warner, "The Contoured-Oxide Monolithic Series-Array Solar Battery," Journal of Applied Physics, vol. 52, pp. 6352-6356, 1981.

[17] E. M. Murray and R. M. Warner, "An Optimization of Monolithic Photo-Voltaic Series Arrays," Journal of Applied Physics, vol. 54, pp. 410-414, 1983.

[18] A. C. Norskog and R. M. Warner, "A Horizontal Monolithic Series-Array Solar Battery Employing Thermomigration," Journal of Applied Physics, vol. 52, pp. 1552-1554, 1981.

[19] R. M. Warner, "Photovoltaic Semi-Conductor Devices," The Regents of the University of Minnestota, Minneapolis, Minn, 1976.

[20] R. M. Warner, "A monolithic series-array solar battery," in 13th IEEE Photovoltaic Specialists Conference, 1978, p. 1116.

[21] R. M. Warner, E. M. Murray, and W. K. Smith, "Monolithic Series-Array Solar-Cell System," Applied Physics Letters, vol. 31, pp. 838-839, 1977. 
[22] S. Wada and Y. Isobe, "Solar battery and method of manufacture," Kabushiki Kaisha Suwa Seikosha, Tokyo, Japan, 1979.

[23] R. I. Frank, "Performance of a new high intensity silicon solar cell," Applied Physics Letters, vol. 34, p. 65, 1979.

[24] R. Kaplow and R. I. Frank, "High-intensity, solid-state-solar cell device," USA: Massachusetts Institute of Technology, Cambridge, 1978.

[25] R. Kaplow and R. I. Frank, "Solar Cell," Massachusetts Institute of Technology, Cambridge, USA, 1978.

[26] R. Kaplow and R. I. Frank, "Method of making a high-intensity solid-state solar cell," Massachusetts Institute of Technology, Cambridge, USA, 1979.

[27] R. Kaplow and R. I. Frank, "Method of making a solar-cell array," USA: Massachusetts Institute of Technology, Cambridge, 1979.

[28] T. I. Chappell, "The V-groove multijunction solar cell," in 13th IEEE Photovoltaic Specialists Conference, 1979, p. 791.

[29] G. R. Moddel, L. A. Christel, and J. F. Gibbons, "Electrically isolated semiconductor integrated photodiode circuits and method," Sera Solar Corporation, Santa Clara, calif., 1986.

[30] R. A. Sinton, "Monolithic series-connected solar cells having improved cell isolation and method of making same," Sun Power Corporation, 1992.

[31] D. D. Krut, D. E. Michaels, and B. T. Cavicchi, "Photovoltaic microarray structure and fabrication method," Spectrolab, Inc., 1995.

[32] J. A. Rand, J. E. Cotter, A. E. Ingram, T. R. Ruffins, K. P. Shreve, R. B. Hall, and A. M. Barnett, "Monolithically integrated silicon-film photovoltaic modules," in 23rd IEEE Photovoltaic Specialist Conference 1993, pp. 214-219.

[33] K. P. Shreve, L. C. DiNetta, J. E. Cotter, J. R. Bower, T. R. Ruffins, and A. M. Barnett, "Initial results for the silicon monolithically interconnected solar cell product," in 25th IEEE Photovoltaic Specialist Conference, 1996, pp. 665-668.

[34] P. E. Sims, A. E. Ingram, E. J. DelleDonne, J. P. Yaskoff, D. H. Ford, J. A. Rand, and A. M. Barnett, "Silicon-on-ceramic monolithically interconnected solar cell modules," in 3rd IEEE World Conference on Photovoltaic Energy Conversion, Osaka, Japan, 2003, pp. 1217-1220.

[35] S. Peters, R. Leihkauf, and H. G. Wagemann, "Integrated series-interconnected thinfilm Si solar cells with $6 \mathrm{~V}$ and $12 \mathrm{~V}$ output voltage," in 3rd World Conference on Photovoltaic Energy Conversion, Osaka, Japan, 2003, pp. 1496-1499.

[36] S. Bermejo, P. Ortega, and L. Castaner, "Fabrication of monolithic photovoltaic minimodules using bulk micromachining techniques," Smart Sensors, Actuators, and Mems, Pts 1 and 2, vol. 5116, pp. 587-595, 2003.

[37] S. Bermejo, P. Ortega, and L. Castañer, "Fabrication of monolithic photovoltaic arrays on crystalline silicon by wafer bonding and deep etching techniques," Progress in Photovoltaics: Research and applications, vol. 13, pp. 617-625, 2005.

[38] A. Hammud, B. Terheiden, R. Auer, and R. Brendel, "Monolithically series-connected crystalline Si wafer cells for portable electronic devices," Conference Record of the Thirty-First IEEE Photovoltaic Specialists Conference - 2005, pp. 1328-1330, 2005.

[39] D. E. Routh, B. R. Hollis, and W. R. Feltner, "Method of construction of a multi-cell solar array," The United States of America as represented by the Administrator of the National Aeronautics and Space Administration, Washington, D.C. , 1979.

[40] J. C. Evans, A.-T. Chai, and C. P. Goradia, "Method of making a high voltage V-groove solar cell," The United States of America as represented by the Administrator of the National Aeronautics and Space Administration, Washington, D.C., 1982.

[41] V. J. Kapoor, G. J. Valco, G. G. Skebe, and J. C. Evans, "High-Voltage Solar-Cell Chip," Journal of Applied Physics, vol. 57, pp. 1343-1346, 1985. 
[42] G. J. Valco, V. J. Kapoor, and J. C. Evans, "Planar Multijunction High-Voltage Solar-Cell Chip," Journal of Applied Physics, vol. 53, pp. 7566-7571, 1982.

[43] M. A. Green, "Integrated solar cells and shunting diodes," Unisearch Limited, Kensington, Australia, 1982.

[44] A. Goetzberger, "Integrated series-connected solar cell," Fed. Rep. of Germany: Fraunhofer Gesellschaft zur Forderung der angewandten Forschung e.v., Munich, , 1982.

[45] R. M. Swanson, "Monolothic series-connected solar cells employing shorted p-n junctions for electrical isolation," Electric Power Research Institute, Palo Alto, Calif., 1990.

[46] R. M. Swanson, "Solar cell having interdigitated contacts and internal bypass diodes," Board of Trustees of the Leland Standford Univ. \& Electric Power Research Institute, Palo Alto, Calif., 1990.

[47] P. Verlinden, R. A. Sinton, R. M. Swanson, and R. A. Crane, "Single-wafer integrated $140 \mathrm{~W}$ silicon concentrator module," in Photovoltaic Specialists Conference, 1991., Conference Record of the Twenty Second IEEE, 1991, pp. 739-743 vol.1.

[48] C. L. Tilford, R. A. Sinton, R. M. Swanson, R. A. Crane, and P. Verlinden, "Development of a 10 kW reflective dish PV system," in Photovoltaic Specialists Conference, 1993. Conference Record of the Twenty Third IEEE, 1993, pp. 1222-1227.

[49] P. Fath, S. Keller, A. Boueke, R. Kuhn, E. Bucher, H. Nussbaumer, and R. Burkhardt, "Progress in the HighVo- and power solar cell," Conference Record of the TwentyEighth leee Photovoltaic Specialists Conference - 2000, pp. 335-338, 2000.

[50] S. Keller, S. Scheibenstock, P. Fath, G. Willeke, and E. Bucher, "Theoretical and experimental behavior of monolithically integrated crystalline silicon solar cells," Journal of Applied Physics, vol. 87, pp. 1556-1563, Feb 2000.

[51] U. Kerst, B. Müller, M. E. Nell, and H. G. Wagemann, "Monolithic seriesinterconnection for a thin film silicon solar cell," Solar Energy Materials and Solar Cells, vol. 65, pp. 471-476, 2001.

[52] S. Kumagai, T. Yamamoto, H. Kubo, and M. Sasaki, "3-D wiring across vertical sidewalls of Si photo cells for series connection and high voltage generation," in Micro Electro Mechanical Systems (MEMS), 2012 IEEE 25th International Conference on, pp. 60-63.

[53] T. Yamamoto, H. Kubo, S. Kumagai, and M. Sasaki, "Micro-power source of Si photo cells connected across vertical sidewalls for light receiving and high voltage generation," in Optical MEMS and Nanophotonics (OMN), 2012 International Conference on, pp. 140-141.

[54] P. Ortega, S. Bermejo, and L. Castañer, "High voltage photovoltaic mini-modules," Progress in Photovoltaics: Research and applications, vol. 16, pp. 369-377, 2008.

[55] S. Bermejo, S. Silvestre, P. Ortega, and G. Herrera, "Light harvesting photovoltaic minigenerator," Progress in Photovoltaics: Research and applications, vol. 20, pp. 967-974, 2008.

[56] S. Bermejo, S. Silvestre, and P. Ortega, "High voltage ultrathin-photovoltaic minimodules: Fabrication technology and application to bioimplantable telesupplying," Microelectronic Engineering, vol. 119, pp. 109-114, 2014.

[57] C. L. Bellew, S. Hollar, and K. S. J. Pister, "An SOI process for fabrication of solar cells, transistors and electrostatic actuators," in TRANSDUCERS, Solid-State Sensors, Actuators and Microsystems, 12th International Conference on, 2003, 2003, pp. 10751078 vol.2.

[58] J. B. Lee, Z. Chen, M. G. Allen, A. Rohatgi, and R. Arya, "A miniaturized high-voltage solar cell array as an electrostatic MEMS power supply," Microelectromechanical Systems, Journal of, vol. 4, pp. 102-108, 1995.

[59] A. Gover and P. Stella, "Vertical multijunction solar-cell one-dimensional analysis," Electron Devices, IEEE Transactions on, vol. 21, pp. 351-356, 1974. 
[60] R. Pozner, G. Segev, R. Sarfaty, A. Kribus, and Y. Rosenwaks, "Vertical junction Si cells for concentrating photovoltaics," Progress in Photovoltaics: Research and applications, vol. 20, pp. 197-208, 2012.

[61] B. L. Sater and N. D. Sater, "High voltage silicon VMJ solar cells for up to 1000 suns intensities," Conference Record of the Twenty-Ninth leee Photovoltaic Specialists Conference 2002, pp. 1019-1022, 2002.

[62] G. Segev and A. Kribus, "Performance of CPV modules based on vertical multi-junction cells under non-uniform illumination," Solar Energy, vol. 88, pp. 120-128, 2013.

[63] P. G. Borden, "A monolithic series-connected Al(0.93)Ga(0.07)As solar cell array," Applied Physics Letters, vol. 35, pp. 553-554, 1979.

[64] P. G. Borden, "Monolithic series-connected solar cell," Varian Associates, Inc., 1981.

[65] K. Masu, S. Quan, M. Konagai, and K. Takahashi, "A monolithic GaAs solar cell array," in 15th IEEE Photovoltaic Specialist Conference, 1981, pp. 1337-1342.

[66] R. P. Gale, R. W. McClelland, B. D. King, and J. V. Gormley, "High-effciency thin film AlGaAs-GaAs double heterostructure solar cells," in 20th IEEE Photovoltaic Specialist Conference, 1988, pp. 446-450.

[67] R. W. McClelland, B. D. Dingle, R. P. Gale, and J. C. C. Fan, "High voltage, monolithically interconnected GaAs thin film solar submodules," in 21th IEEE Photovoltaic Specialist Conference, 1990, pp. 168-171.

[68] M. B. Spitzer, R. W. McClelland, B. D. Dingle, D. S. Hill, and B. H. Rose, "Monolithic series-connected gallium arsenide converters development," in 22nd Photovoltaic Specialists Conference, 1991, pp. 142-146.

[69] B. D. Dingle, M. B. Spitzer, R. W. McClelland, J. C. C. Fan, and P. M. Zavracky, "Monolithic integration of a light-emitting diode array and silicon circuit using transfer process," Applied Physics Letters, vol. 62, pp. 2760-2762, 1993.

[70] B. Beaumont, J.-C. Guillaume, M. F. Vilela, A. Saletes, and C. Verie, "High efficiency conversion of laser energy and its application to optical power transmission," in 22nd IEEE Photovoltaic Specialist Conference, Las Vegas, 1991, pp. 1503-1507.

[71] A. L. Fahrenbruch, A. Lopez-Otero, J. G. Werthen, and T.-C. Wu, "GaAs- and InAIGaAsbased concentrator-type cells for conversion of power transmitted by optical fibers," in 25th IEEE Photovoltaic Specialist Conference, Washington, D.C., 1996, pp. 117-120.

[72] R. Pena and C. Algora, "Mismatch losses in GaAs monolithically series connected photovoltaic converters for monochromatic illumination," in 16th European Photovoltaic Solar Energy Conference, Glasgow, UK, 2000.

[73] R. Pena and C. Algora, "Evaluation of mismatch and non-uniform illumination losses in monolithically series-connected GaAs photovoltaic converters," Progress in Photovoltaics, vol. 11, pp. 139-150, Mar 2003.

[74] R. Pena and C. Algora, "The influence of post-growth manufacturing technology on the efficiency of multiple photovoltaic converters," in 21st European Photovoltaic Solar Energy Conference, Dresden, Germany, 2006, pp. 477-480.

[75] R. Pena, C. Algora, and I. Anton, "GaAs multiple photovoltaic converters with an efficiency of $45 \%$ for monochromatic illumination," Proceedings of 3rd World Conference on Photovoltaic Energy Conversion, Vols a-C, pp. 228-231, 2003.

[76] R. Pena and E. Algora, "The influence of monolithic series connection on the efficiency of GaAs photovoltaic converters for monochromatic illumination," leee Transactions on Electron Devices, vol. 48, pp. 196-203, Feb 2001.

[77] R. Rieske, S. Sohr, K. Nieweglowski, and K. J. Wolter, "Assembly tolerance requirements for photonics packaging of multi-cell laser power converters," in Electronic System-Integration Technology Conference (ESTC), 2012 4th, Amsterdam, 2012, pp. 1-6.

[78] S. Sohr, R. Rieske, K. Nieweglowski, and K. J. Wolter, "Assembly tolerant design of multi-cell laser power converters for wafer-level photonic packaging," in Electronic 
Components and Technology Conference (ECTC), 2013 IEEE 63rd, Las Vegas, 2013, pp. 1866-1873.

[79] D. Krut, R. Sudharsanan, W. Nishikawa, T. Isshiki, J. Ermer, and N. H. Karam, "Monolithic multi-cell GaAs laser power converter with very high current density," in 29th IEEE Photovoltaic Specialist Conference, New Orleans, LA, 2002, pp. 908-911.

[80] D. M. Wilt, C. S. Murray, N. S. Fatemi, and V. G. Weizer, " $n / p / n$ tunnel junction InGaAs monolithic interconnected module (MIM)," in 4th NREL Conference on Thermophotovoltaic Generation of Electricity, Denver, CO, USA, 1998, pp. 152-160.

[81] A. W. Bett, F. Dimroth, R. Lockenhoff, E. Oliva, and J. Schubert, "III-V solar cells under monochromatic illumination," in 33rd IEEE Photovoltaic Specialists Conference, San Diego, 2008, pp. 1-5.

[82] J. Schubert, E. Oliva, F. Dimroth, W. Guter, R. Loeckenhoff, and A. W. Bett, "HighVoltage GaAs Photovoltaic Laser Power Converters," IEEE Transactions on Electron Devices, vol. 56, pp. 0018-9383, 2009.

[83] C. E. Valdivia, M. M. Wilkins, B. Bouzazi, A. Jaouad, V. Aimez, R. ArÃ“s, D. P. Masson, S. Fafard, and K. Hinzer, "Five-volt vertically-stacked, single-cell GaAs photonic power converter," in Proc. SPIE, San Francisco, 2015, pp. 93580E-93580E-8.

[84] J. S. Ward, A. Duda, K. Zweibel, and T. J. Coutts, "Large-area, high intensity PV arrays for systems using dish concentrating optics," in 2nd World conference and exhibition on photovoltaic solar energy conversion, Vienna, Austria, 1998, pp. 14-18.

[85] J. S. Ward, A. Duda, M. W. Wanlass, J. J. Carapella, X. Wu, R. J. Matson, T. J. Coutts, and T. Moriarty, "A novel design for monolithically interconnected modules (MIMs) for Thermophotovoltaic Power Conversion," in 3rd NREL Conference on Thermophotovoltaic Generation of Electricity, Colorado, USA, 1997, pp. 227-236.

[86] S. van Riesen, F. Dimroth, and A. W. Bett, "Fabrication of MIM-GaAs solar cells for high concentration PV," in 3rd World Conference on Photovoltaic Energy Conversion, Osaka, Japan, 2003, pp. 833-836.

[87] S. Van Riesen, R. Loeckenhoff, F. Dimroth, and A. W. Bett, "GaAs-monolithically intyerconnected modules (MIMS) with an efficiency above 20\%," in 19th European Photovoltaic Solar Energy Conference, Paris, France, 2004, pp. 150-153.

[88] R. Loeckenhoff, S. Van Riesen, M. Meusel, F. Dimroth, and A. W. Bett, "Large area monolithic interconnected modules (MIMS) for compact concentrator modules," in 20th European Photovoltaic Solar Energy Conference, Barcelona, Spain, 2005, pp. 8689.

[89] R. Loeckenhoff, G. Dibowski, F. Dimroth, M. Meusel, S. Van Riesen, and A. W. Bett, "1000 Sun, Compact Receiver Based on Monolithic Interconnected Modules (MIMS)," in 4th IEEE World Conference on Photovoltaic Energy Conversion, 2006, pp. 737-740.

[90] D. Faiman, S. Biryukov, D. Bokovza, S. Kabalo, E. A. Katz, V. Melnichak, A. W. Bett, R. Loeckenhoff, and C. Zahler, "Natural Sunlight Tests at Petal, of A Trial Mim String at Concentrations up to 1000X," in 4th IEEE World Conference on Photovoltaic Energy Conversion, 2006, pp. 710-713.

[91] O. Pereles, A. W. Bett, R. Loeckenhoff, E. Lupfert, A. Haberle, J. Fernández, G. Strobl, D. Faiman, R. Soler, and C. Yousif, "High concentrator PV system," in 4th International Conference on Solar Concentrators for the Generation of Electricity or Hydrogen, El Escorial, Spain, 2007, pp. 253-255.

[92] R. Loeckenhoff, J. Wilde, F. Dimroth, and A. W. Bett, "Approaches to large area III-V concentrator receivers," in 21st European Photovoltaic Solar Energy Conference, Dresden, Germany, 2006.

[93] R. Loeckenhoff, F. Dimroth, E. Oliva, A. Ohm, J. Wilde, D. Faiman, S. Biryukov, V. Melnichak, S. Kabalo, D. Bokovza, and A. W. Bett, "Development, Characterisation and 1000 suns outdoor tests of GaAs monolithic interconnected module (MIM) receivers," Progress in Photovoltaics: Research and applications, vol. 16, pp. 101-112, 2008. 
[94] S. Zimmermann, H. Helmers, M. K. Tiwari, W. Escher, S. Paredes, P. Neves, D. Poulikakos, M. Wiesenfarth, A. W. Bett, and B. Michel, "Advanced liquid cooling in HCPVT systems to achieve higher energy efficiencies," AIP Conference Proceedings, vol. 1556, pp. 248-251, 2013.

[95] M. Wiesenfarth, H. Helmers, S. P. Philipps, M. Steiner, and A. W. Bett, "Advanced Concepts in Concentrating Photovoltaic (CPV)," in 27th European Photovoltaic Solar Energy Conference, Frankfurt, Germany, 2012, pp. 477-480.

[96] M. Seno, K. Watanabe, M. Sugiyama, and Y. Nakano, "Performance of monolithic integrated series-connected GaAs solar cells under concentrated light," AIP Conference Proceedings, vol. 1556, pp. 26-29, 2013.

[97] K. Watanabe, Y. Yamada, M. Senou, M. Sugiyama, and Y. Nakano, "Fabrication of Monolithic Integrated Series-Connected GaAs Photovoltaic Cells for Concentrator Applications," Japanese Journal of Applied Physics, vol. 51, p. 10ND18, 2012.

[98] J. Ohsawa, M. Kawasaki, T. Tanaka, N. Tsuchida, S. Hayakawa, and M. Yoshida, "A GaAs Micro Solar Cell with Output Voltage over 20 V," Japanese Journal of Applied Physics, vol. 38, p. 6947, 1999.

[99] J. Ohsawa, K. Shono, and Y. Hiei, "High-voltage micro solar cell arrays of GaAs with output voltage up to $100 \mathrm{~V}$," in Optical MEMs, 2002. Conference Digest. 2002 IEEE/LEOS International Conference on, 2002, pp. 103-104.

[100] Y. Wang, N. Chen, X. Zhang, Y. Bai, Y. Wang, T. Huang, H. Zhang, and H. Shi, "Analysis of leakage current in GaAs micro-solar cell arrays," Science China Technological Sciences, vol. 53, pp. 1240-1246, 2010.

[101] Y. Bai, J. Wang, Y. Wang, H. Zhang, N. Chen, J. Yao, T. Huang, Y. Wang, X. Zhang, and J. $\mathrm{Wu}$, "Improved performance of GaAs-based micro-solar cell with novel polyimide/SiO2/TiAu/SiO2 structure," Science China Technological Sciences, vol. 54, pp. 830-834, 2011.

[102] A. Belghachi and S. Khelifi, "Modelling of the perimeter recombination effect in GaAsbased micro-solar cell," Solar Energy Materials and Solar Cells, vol. 90, pp. 1-14, 2006.

[103] W. W. Ng, K. Nakano, Y. Z. Liu, and P. D. Dapkus, "A monolithic GalnAsP/InP photovoltaic power converter," IEEE Transactions on Electron Devices, vol. 29, pp. 1449-1454, 1982.

[104] R. E. Haigh, S. Wojtczuk, G. F. Jacobson, and K. G. Hagans, "High voltage photovoltaic power converter," Univ California (Regc), 2000.

[105] S. Wojtczuk, "Long-wavelength laser power converters for optical fibers," in 26th Photovoltaic Specialists Conference, 1997, pp. 971-974.

[106] S. Wojtczuk, T. Parados, and G. Walker, "P/N In(Al)GaAs multijunction laser power converters," in 13th Space Photovoltaic Research and Technology Conference, Cleveland, OH, 1994.

[107] S. Wojtczuk, "Comparision of $0.55 \mathrm{eV}$ InGaAs single-junction vs. multi-junction TPV technology," in 3rd NREL Conference on Thermophotovoltaic Generation of Electricity, Colorado Springs, CO, 1997, pp. 205-213.

[108] D. M. Wilt, N. S. Fatemi, P. P. Jenkins, R. W. Hoffman, G. A. Landis, and R. K. Jain, "Monolithically interconnected InGaAs TPV module development," in 25th Photovoltaic Specialists Conference, Washington D.C., USA, 1996, pp. 43-48.

[109] D. M. Wilt, N. S. Fatemi, P. P. Jenkins, V. G. Weizer, R. W. Hoffman Jr, R. K. Jain, C. S. Murray, and D. R. Riley, "Electrical and optical performance characteristics of $0.74 \mathrm{eV}$ $\mathrm{p} / \mathrm{n}$ InGaAs monolithic interconnected modules," in 3rd NREL Conference on Thermophotovoltaic Generation of Electricity, Colorado Springs, CO, USA, 1997, pp. 237-247.

[110] D. M. Wilt, N. S. Fatemi, P. P. Jenkins, V. G. Weizer, R. W. Hoffman, C. S. Murray, and D. Riley, "Electrical and optical performance characteristics of $\mathrm{p} / \mathrm{n}$ InGaAs monolithic 
interconnected modules," in 32nd Intersociety Energy Conversion Engineering Conference, Hawai, 1997, pp. 1119-1124.

[111] N. S. Fatemi, D. M. Wilt, P. P. Jenkins, R. W. Hoffman Jr, V. G. Weizer, C. S. Murray, and D. Riley, "Materials and Process development for the monolithic interconnected module (MIM) InGaAs/InP TPV deviced," in 3rd NREL Conference on Thermophotovoltaic Generation of Electricity, Colorado Springs, CO, USA, 1997, pp. 249-262.

[112] N. S. Fatemi, D. M. Wilt, P. P. Jenkins, V. G. Weizer, R. W. Hoffman, C. S. Murray, D. Scheiman, D. Brinker, and D. Riley, "InGaAs monolithic interconnected modules (MIMs)," in 26th Photovoltaic Specialists Conference, Anaheim, CA, 1997, pp. 799-804.

[113] J. S. Ward, M. W. Wanlass, and T. A. Gessert, "Interdigitated photovoltaic power conversion device," Midwest Research Institute, Kansas City, Mo., 1999.

[114] N. S. Fatemi, D. M. Wilt, R. W. Hoffman Jr, M. A. Stan, V. G. Weizer, P. P. Jenkins, O. S. Khan, C. S. Murray, D. Scheiman, and D. Brinker, "High-performance, latticemismatched InGaAs/InP monolithic interconnected modules (MIMs)," in 4th NREL Conference on Thermophotovoltaic Generation of Electricity, Denver, CO, USA, 1998, pp. 121-131.

[115] S. A. Ringel, R. N. Sacks, L. Qin, M. B. Clevenger, and C. S. Murray, "Growth and properties of InGaAs/FeAl/InAlAs/InP heterostructures for buried reflector/interconnect applications in InGaAs thermophotovoltaic devices," in 4th NREL Conference on Thermophotovoltaic Generation of Electricity, Denver, CO, USA, 1998, pp. 142-151.

[116] C. T. Ballinger, G. W. Charache, and C. S. Murray, "Monte Carlo analysis of a monolithic interconnected module with a back surface reflector," in 4th NREL Conference on Thermophotovoltaic Generation of Electricity, Denver, CO, USA, 1998, pp. 161-174.

[117] C. S. Murray and D. M. Wilt, "Monolithic interconnected module with a tunnel junction for enhamced electrical and optical performance," The United States of America as represented vy the United States Department of Energy, 2000.

[118] D. M. Wilt, E. B. Clark, M. B. Clevenger, C. S. Murray, and R. J. Wehrer, "0.55 eV n/p/n MIM TPV cell development," in 28th Photovoltaic Specialists Conference, 2000, pp. 1024-1027.

[119] C. S. Murray, N. S. Fatemi, M. Stan, B. Wernsman, and R. J. Wehrer, "Growth, processing and characterization of $0.55-\mathrm{eV} \mathrm{n} / \mathrm{p} / \mathrm{n}$ monolithic interconnected modules," in 28th IEEE Photovoltaic Specialist Conference, 2000, pp. 1238-1241.

[120] M. W. Wanlass, J. J. Carapella, A. Duda, K. Emery, L. Gedvilas, T. Moriarty, J. S. Ward, J. D. Webb, X. Wu, and C. S. Murray, "High-performance, 0.6-eV, Ga0.32In0.68As/InAs0.32P0.68 thermophotovoltaic converters and monolithically interconnected modules," in 4th NREL Conference on Thermophotovoltaic Generation of Electricity, Denver, CO, USA, 1998, pp. 132-141.

[121] J. G. Cederberg, J. D. Blaich, G. R. Girard, S. R. Lee, D. P. Nelson, and C. S. Murray, "The development of (InGa)As thermophotovoltaic cells on InP using strain-relaxed In(PAs) buffers," Journal of Crystal Growth, vol. 310, pp. 3453-3458, 2008.

[122] M. K. Hudait, M. Brenner, and S. A. Ringel, "Metamorphic In0.7Al0.3As/In0.69Ga0.31As thermophotovoltaic devices grown on graded InAsyP1â^y buffers by molecular beam epitaxy," Solid-state electronics, vol. 53, pp. 102-106, 2009.

[123] D. Wilt, R. Wehrer, M. Palmisiano, M. Wanlass, and C. Murray, "Monolithic interconnected modules (MIMs) for thermophotovoltaic energy conversion," Semiconductor Science and Technology, vol. 18, pp. S209-S215, May 2003.

[124] M. W. Wanlass, S. P. Ahrenkiel, R. K. Ahrenkiel, J. J. Carapella, R. J. Wehrer, and B. Wernsman, "Recent advances in low-bandgap, InP-based GalnAs/InAsP materials and 
devices for thermophotovoltaic (TPV) energy conversion," in 6th Conference on Thermophotovoltaic Generation of Electricity, Freiburg, Germany, 2004, pp. 427-435.

[125] B. Wernsman, R. Siergiej, S. D. Link, R. G. Mahorter, M. N. Palmisiano, R. J. Wehrer, R. W. Schultz, G. P. Schmuck, R. L. Messham, S. Murray, C. S. Murray, F. Newman, D. Taylor, D. M. DePoy, and T. Rahmlow, "Greater than 20\% radiant heat conversion efficiency of a thermophotovoltaic radiator/module system using reflective spectral control," IEEETransactions on Electron Devices, vol. 51, pp. 0018-9383, 2004.

[126] C. S. Murray, F. Newman, S. Murray, J. Hills, D. Aiken, R. Siergiej, B. Wernsman, and D. Taylor, "Multi-wafer growth and processing of $0.6-\mathrm{eV}$ InGaAs monolithic interconnected modules," in 29th IEEE Photovoltaic Specialist Conference, 2002, pp. 888-891.

[127] R. R. Siergiej, B. Wernsman, S. A. Derry, R. G. Mahorter, R. J. Wehrer, S. D. Link, M. N. Palmisiano, R. L. Messham, S. Murray, C. S. Murray, F. Newman, J. Hills, and D. Taylor, "20\% efficient InGaAs/InPAs thermophotovoltaic cells," in 5th Conference on Thermophotovoltaic Generation of Electricity, Rome, Italy, 2002, pp. 414-423.

[128] S. L. Murray, C. S. Murray, M. A. Stan, F. D. Newman, J. Hills, R. Siergiej, and B. Wernsman, "Effect of metal coverage on the performance of 0.6-eV InGaAs monolithic interconnected modules," in 5th Conference on Thermophotovoltaic Generation of Electricity, Rome, Italy, 2002, pp. 424-433.

[129] F. D. Newman, I. Aeby, T. Varghese, S. P. Endicter, G. Girard, M. V. Turner, A. C. Sandoval, J. N. Fiedor, S. D. Link, D. Llera-Hurlburt, R. Siergiej, M. W. Dashiell, and H. Ehsani, "Pilot-Production Yield of Indium Phosphide-Based Thermophotovoltaic Monolithically Interconnected Modules," in 4th IEEE World Conference on Photovoltaic Energy Conversion, 2006, pp. 663-666.

[130] N. Su, P. Fay, S. Sinharoy, D. Forbes, and D. Scheiman, "Characterization and modeling of InGaAs/InAsP thermophotovoltaic converters under high illumination intensities," Journal of Applied Physics, vol. 101, p. 064511, 2007.

[131] D. Wilt, D. Chubb, D. Wolford, P. Magari, and C. Crowley, "Thermophotovoltaics for Space Power Applications," AIP Conference Proceedings, vol. 890, pp. 335-345, 2007.

[132] M. W. Wanlass, "Electrical isolation of component cells in monolithically interconnected modules," Midwest Research Institute, 2001.

[133] R. J. Wehrer, M. W. Wanlass, B. Wernsman, J. J. Carapella, S. P. Ahrenkiel, D. M. Wilt, and C. S. Murray, "0.74/0.55-eV GaxIn1-xAs/InAsP1-y monolithic, tandem, MIM TPV converters: design, growth, processing and performance," in 29th Photovoltaic Specialists Conference, 2002, pp. 884-887.

[134] M. N. Palmisiano, R. M. Biefeld, J. G. Cederberg, M. J. Hafich, and G. M. Peake, "Development of InGaAsSb based monolithic interconnected modules (MIMs)," in 5th Conference on Thermophotovoltaic Generation of Electricity, Rome, Italy, 2002, pp. 305-313.

[135] C. A. Wang, R. K. Huang, M. K. Connors, D. A. Shiau, P. G. Murphy, P. W. O'Brien, A. C. Anderson, D. Donetsky, S. Anikeev, G. Belenky, S. Luryi, and G. Nichols, "Monolithic series-interconnected GalnAsSb/AlGaAsSb thermophotovoltaic devices wafer bonded to GaAs," in 6th Conference on Thermophotovoltaic Generation of Electricity, Freiburg, Germany, 2004, pp. 294-302.

[136] C. A. Wang, R. K. Huang, D. A. Shiau, M. K. Connors, P. G. Murphy, P. W. O'Brien, A. C. Anderson, D. M. DePoy, G. Nichols, and M. N. Palmisiano, "Monolithically seriesinterconnected GalnAsSb/AlGaAsSb/GaSb thermophotovoltaic devices with an internal backsurface reflector formed by wafer bonding," Applied Physics Letters, vol. 83, pp. 1286-1288, Aug 2003.

[137] C. A. Wang, P. G. Murphy, P. W. O'Brien, D. A. Shiau, A. C. Anderson, Z. L. Liau, D. M. DePoy, and G. Nichols, "Wafer-Bonded Internal Back-Surface Reflectors for enhanced 
TPV performance," in 5th Conference on Thermophotovoltaic Generation of Electricity, Rome, Italy, 2002, pp. 473-481.

[138] C. A. Wang, D. A. Shiau, P. G. Murphy, P. W. O’Brien, R. K. Huang, M. K. Connors, A. C. Anderson, D. Donetsky, S. Anikeev, G. Belenky, D. M. Depoy, and G. Nichols, "Wafer bonding and epitaxial transfer of GaSb-based epitaxy to GaAs for monolithic interconnection of thermophotovoltaic devices," Journal of Electronic Materials, vol. 33, pp. 213-217, 2004.

[139] J. M. Borrego, E. Brown, P. Greiff, D. L. Huffaker, R. B. Laghumavarapu, J. Kim, and P. S. Dutta, "Rear illumination monolithically integrated GaSb thermophotovoltaic devices grown on semi-insulating GaAs substrate," Journal of Renewable and Sustainable Energy, vol. 6, p. 011207, 2014.

[140] K. Jung Min, S. D. Partha, B. Eric, M. B. Jose, and G. Paul, "Wafer-scale processing technology for monolithically integrated GaSb thermophotovoltaic device array on semi-insulating GaAs substrate," Semiconductor Science and Technology, vol. 28, p. 065002, 2013.

[141] J. Min Kim, P. S. Dutta, E. Brown, J. M. Borrego, and P. Greiff, "Wet chemical etching process for wafer scale isolation and interconnection of GaSb based device layers grown on GaAs substrates," Journal of Vacuum Science \& Technology B, vol. 31, p. 031204, 2013.

[142] P. G. Borden, "Three-Terminal solar cell circuit," Varian Associates, Inc., 1985.

[143] P. G. Borden and R. R. Saxena, "Cascade solar cell having conductive interconnects," Varian Associates, Inc., 1982.

[144] M. W. Wanlass, "Monolithic tandem solar cell," The United States of America as represented by the United States Department of Energy, 1994.

[145] M. W. Wanlass, "Monolithic tandem solar cell," The United States of America as represented by the United States Department of Energy, Washington, D.C., 1991.

[146] K. I. Chang and D. R. Lillington, "Monolithically integrated solar cell microarray and fabrication method," Spectrolab, Inc., 1997.

[147] M. W. Wanlass and A. Mascarenhas, "Voltage-Matched, Monolithic, Multi-Band Gap Devices," 2003.

[148] R. J. Wehrer, M. W. Wanlass, D. M. Wilt, B. Wernsman, R. Siergiej, and J. J. Carapella, "InGaAs series-connected, tandem, MIM TPV converters," in 3rd World Conference on Photovoltaic Energy Conversion, Osaka, Japan, 2003, pp. 892-895.

[149] R. J. Wehrer, M. W. Wanlass, D. Taylor, B. Wernsman, J. J. Carapella, R. W. Schultz, R. K. Ahrenkiel, D. M. Wilt, M. W. Dashiell, R. Siergiej, S. D. Link, and R. L. Messham, "0.52 $\mathrm{eV}$ InGaAs/InPAs thermophotovoltaic cells," in 6th Conference on Thermophotovoltaic Generation of Electricity, Freiburg, Germany, 2004, pp. 445-452.

[150] D. M. Wilt, R. J. Wehrer, W. F. Maurer, P. P. Jenkins, B. Wernsman, and R. W. Schultz, "Buffer layer effects on tandem InGaAs TPV devices," in 6th Conference on Thermophotovoltaic Generation of Electricity, Freiburg, Germany, 2004, pp. 453-461.

[151] M. W. Wanlass and D. S. Albin, "A rigorous analysis of series-connected, multibandgap, tandem thermophotovoltaic (TPV) energy converters," in 6th Conference on Thermophotovoltaic Generation of Electricity, Freiburg, Germany, 2004, pp. 462-470.

[152] R. Siergiej, S. Sinharoy, T. Valko, R. J. Wehrer, B. Wernsman, S. D. Link, R. W. Schultz, and R. L. Messham, "InGaAsP/InGaAs tandem TPV device," in 6th Conference on Thermophotovoltaic Generation of Electricity, Freiburg, Germany, 2004, pp. 480-488.

[153] F. Newman, T. Varghese, I. Aeby, A. C. Sandoval, M. V. Turner, S. P. Endicter, G. Girard, J. N. Fiedor, R. Siergiej, B. Wernsman, R. J. Wehrer, and J. P. Maranchi, "LatticeMismatched InGaAsP and AlGalnAs Quaternary Materials for Thermophotovoltaic Applications," in 4th IEEE World Conference on Photovoltaic Energy Conversion, 2006, pp. 659-662. 
[154] H. Helmers, E. Oliva, W. Bronner, F. Dimroth, and A. W. Bett, "Advanced Processing Techniques Used for the Development of DualJunction Monolithic Interconnected Modules," AIP Conference Proceedings, vol. 1277, pp. 39-42, 2010.

[155] H. Helmers, E. Oliva, W. Bronner, F. Dimroth, and A. W. Bett, "Processing Techniques for Monolithic Interconnection of Solar Cells at Wafer Level," IEEE Transactions on Electron Devices, vol. 57, pp. 3355-3360, 2008.

[156] K. Watanabe, M. Seno, M. Sugiyama, and Y. Nakano, "Development of the monolighically interconnected InGaP/GaAs dual junction solar cell with bypass diode for ultrahigh concentrator application," in 40th IEEE Photovoltaic Specialist Conference (PVSC), Denver, 2014, pp. 0559-0561.

[157] T. Akatsu, C. Deguet, L. Sanchez, F. Allibert, D. Rouchon, T. Signamarcheix, C. Richtarch, A. Boussagol, V. Loup, F. Mazen, J.-M. Hartmann, Y. Campidelli, L. Clavelier, F. Letertre, N. Kernevez, and C. Mazure, "Germanium-on-insulator (GeOI) substrates-A novel engineered substrate for future high performance devices," Materials Science in Semiconductor Processing, vol. 9, pp. 444-448, 2006.

[158] Y. B. Cheng, C. K. Chia, Y. Chai, and D. Z. Chi, "High quality Ge epitaxy on GaAs (100) grown by metal-organic chemical vapor deposition," Thin Solid Films, vol. 522, pp. 340344, 2012.

[159] V. Sabnis, H. Yuen, and M. Wiemer, "High-efficiency multijunction solar cells employing dilute nitrides," AIP Conference Proceedings, vol. 1477, pp. 14-19, 2012.

[160] N. J. Ekins-Daukes, J. M. Barnes, K. W. J. Barnham, J. P. Connolly, M. Mazzer, J. C. Clark, R. Grey, G. Hill, M. A. Pate, and J. S. Roberts, "Strained and strain-balanced quantum well devices for high-efficiency tandem solar cells," Solar Energy Materials and Solar Cells, vol. 68, pp. 71-87, 2001.

[161] R. L. Woo, W. D. Hong, S. Mesropian, M. S. Leite, H. A. Atwater, and D. C. Law, "First demonstration of monolithic InP-based InAlAs/InGaAsP/InGaAs triple junction solar cells," in Photovoltaic Specialists Conference (PVSC), 2011 37th IEEE, 2011, pp. 000295000298.

[162] D. C. Law, R. R. King, H. Yoon, M. J. Archer, A. Boca, C. M. Fetzer, S. Mesropian, T. Isshiki, M. Haddad, K. M. Edmondson, D. Bhusari, J. Yen, R. A. Sherif, H. A. Atwater, and N. H. Karam, "Future technology pathways of terrestrial III-V multijunction solar cells for concentrator photovoltaic systems," Solar Energy Materials and Solar Cells, vol. 94, pp. 1314-1318, 2010.

[163] F. Dimroth, M. Grave, P. Beutel, U. Fiedeler, C. Karcher, T. N. D. Tibbits, E. Oliva, G. Siefer, M. Schachtner, A. Wekkeli, A. W. Bett, R. Krause, M. Piccin, N. Blanc, C. Drazek, E. Guiot, B. Ghyselen, T. Salvetat, A. Tauzin, T. Signamarcheix, A. Dobrich, T. Hannappel, and K. Schwarzburg, "Wafer bonded four-junction GalnP/GaAs//GalnAsP/GalnAs concentrator solar cells with $44.7 \%$ efficiency," Progress in Photovoltaics: Research and Applications, vol. 22, pp. 277-282, 2014.

[164] B.-C. Juang, R. B. Laghumavarapu, B. J. Foggo, P. J. Simmonds, A. Lin, B. Liang, and D. L. Huffaker, "GaSb thermophotovoltaic cells grown on GaAs by molecular beam epitaxy using interfacial misfit arrays," Applied Physics Letters, vol. 106, p. 111101, 2015.

[165] D. DeMeo, C. Shemelya, C. Downs, A. Licht, E. S. Magden, T. Rotter, C. Dhital, S. Wilson, G. Balakrishnan, and T. E. Vandervelde, "GaSb Thermophotovoltaic Cells Grown on GaAs Substrate Using the Interfacial Misfit Array Method," Journal of Electronic Materials, vol. 43, pp. 902-908, 2014.

[166] S. Huang, G. Balakrishnan, and D. L. Huffaker, "Interfacial misfit array formation for GaSb growth on GaAs," Journal of Applied Physics, vol. 105, p. 103104, 2009.

[167] C. J. Reyner, J. Wang, K. Nunna, A. Lin, B. Liang, M. S. Goorsky, and D. L. Huffaker, "Characterization of GaSb/GaAs interfacial misfit arrays using x-ray diffraction," Applied Physics Letters, vol. 99, p. 231906, 2011. 
[168] M. Grzesik, S. R. Vangala, and W. D. Goodhue, "Indirect Wafer Bonding and Epitaxial Transfer of GaSb-Based Materials," Journal of Electronic Materials, vol. 42, pp. 679683, 2013.

[169] Y. Zheng, P. D. Moran, Z. F. Guan, S. S. Lau, D. M. Hansen, T. F. Kuech, T. E. Haynes, T. Hoechbauer, and M. Nastasi, "Transfer of n-type GaSb onto GaAs substrate by hydrogen implantation and wafer bonding," Journal of Electronic Materials, vol. 29, pp. 916-920, 2000.

[170] H. Mark, M. Trevor, and S. Peter, "III-V semiconductor devices integrated with silicon," Semiconductor Science and Technology, vol. 28, p. 090301, 2013.

[171] D.-M. Geum, M.-S. Park, J. Y. Lim, H.-D. Yang, J. D. Song, C. Z. Kim, E. Yoon, S. Kim, and W. J. Choi, "Ultra-high-throughput Production of III-V/Si Wafer for Electronic and Photonic Applications," Scientific Reports, vol. 6, p. 20610, 2016.

[172] F. Predan, D. Reinwand, V. Klinger, and F. Dimroth, "Transparent and electrically conductive $\mathrm{GaSb} / \mathrm{Si}$ direct wafer bonding at low temperatures by argon-beam surface activation," Applied Surface Science, vol. 353, pp. 1203-1207, 2015. 


\begin{tabular}{|c|c|c|c|c|c|c|c|}
\hline $\begin{array}{c}\text { MIM } \\
\text { structure }\end{array}$ & $\begin{array}{c}\text { Number of cells } \\
\text { of the MIM }\end{array}$ & $\begin{array}{l}\text { Type of } \\
\text { isolation }\end{array}$ & Substrate & Application & Illumination & Electrical characteristics & Reference \\
\hline \multirow{2}{*}{ 1J-Si EMVJ } & \multirow{2}{*}{$\begin{array}{c}\text { 1/4/18 cells show } \\
\text { same results } \\
\text { (proportional } \\
\left.V_{\mathrm{OC}}\right)\end{array}$} & \multirow{2}{*}{$\begin{array}{c}\text { SOI } \\
\text { (isolation } \\
\text { baskets) }\end{array}$} & \multirow{2}{*}{\begin{tabular}{|c|}
$10 \Omega \mathrm{cm}$ n-type \\
float-zone \\
single-crystal \\
Si on glass
\end{tabular}} & \multirow{2}{*}{$\mathrm{CPV}$} & 1 sun $(\mathrm{AM} 1)$ & $\begin{array}{c}J_{\mathrm{SC}}=32 \mathrm{~mA} / \mathrm{cm}^{2} ; V_{\mathrm{OC}}=0.54 \mathrm{~V} ; \\
F F=0.74 ; \text { Eff. }=12.8 \%\end{array}$ & \multirow{2}{*}{ [23] } \\
\hline & & & & & $\begin{array}{l}300 \text { suns } \\
(\mathrm{AM} 1)\end{array}$ & $\begin{array}{c}J_{\mathrm{SC}}=9,6 \mathrm{~A} / \mathrm{cm}^{2} ; V_{\mathrm{OC}}=\mathrm{O} .77 \mathrm{~V} ; \\
F F=0.77 ; \text { Eff. }=19 \%\end{array}$ & \\
\hline $\begin{array}{c}1 \mathrm{~J}-\mathrm{Si} \\
\text { anisotropic } \\
\text { etching }\end{array}$ & $\begin{array}{l}43 \text { series- } \\
\text { connected cells }\end{array}$ & $\begin{array}{l}\text { SOI (V- } \\
\text { grooves) }\end{array}$ & $\begin{array}{c}\text { Intrinsic } \\
\text { single-crystal } \\
\text { Si on glass }\end{array}$ & $\mathrm{CPV}$ & $\begin{array}{l}300 \text { suns } \\
(\mathrm{AM} 1)\end{array}$ & $\begin{array}{c}J_{\mathrm{SC}}=192.6 \mathrm{~A} / \mathrm{cm}^{2} ; V_{\mathrm{OC}}=30.2 \mathrm{~V} \\
F F=0.63 ; \text { Eff. }=12.2 \%\end{array}$ & [28] \\
\hline $\begin{array}{c}1 \mathrm{~J}-\text { Si selective } \\
\text { etching }\end{array}$ & - & $\begin{array}{l}\text { SOI (V- } \\
\text { grooves) }\end{array}$ & $\begin{array}{c}\text { Thin } \\
\text { crystalline } \mathrm{Si} \\
\text { on glass }\end{array}$ & $\begin{array}{l}\text { Terrestrial } \\
\text { and space } \\
\text { solar cells }\end{array}$ & $\begin{array}{c}1 \text { sun } \\
(\mathrm{AM} 1.5 \mathrm{G})\end{array}$ & $\begin{array}{c}J_{\mathrm{SC}}=3.14 \mathrm{~mA} / \mathrm{cm}^{2} ; V_{\mathrm{OC}}=5.5 \mathrm{~V} \\
F F=0.645 ; \text { Eff. }=11.1 \%\end{array}$ & [33] \\
\hline $\begin{array}{l}\text { WSI module } \\
\text { with BPC } \\
\text { structure. }\end{array}$ & $\begin{array}{l}2 \text { parallel strings } \\
\text { of } 5 \text { series- } \\
\text { connected cells } \\
\text { (10 cells })\end{array}$ & \begin{tabular}{|c|} 
Shorted $\mathrm{p}-$ \\
$\mathrm{n}$ junctions \\
in the \\
perimeter
\end{tabular} & 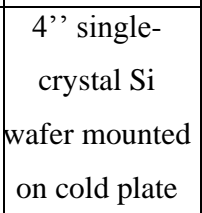 & $\mathrm{CPV}$ & 57.9 suns & $\begin{array}{c}J_{\mathrm{SC}}=421.9 \mathrm{~mA} / \mathrm{cm}^{2}\left(211 \mathrm{~mA} / \mathrm{cm}^{2}\right. \\
\text { per string }) ; V_{\mathrm{OC}}=3.8 \mathrm{~V} ; \\
F F=0.794 ; \text { Eff. }=22 \%\end{array}$ & {$[47]$} \\
\hline $\begin{array}{c}1 \mathrm{~J}-\text { Si selective } \\
\text { etching }\end{array}$ & $\begin{array}{c}169 \text { cells }(0.225 \\
\left.\mathrm{mm}^{2} \text { each }\right)\end{array}$ & $\begin{array}{c}\text { Isolation } \\
\text { trenches by } \\
\text { anisotropic } \\
\text { etching }\end{array}$ & $\begin{array}{l}1-5 \Omega \mathrm{cm} \text { p- } \\
\text { type c-Si } 4, \\
\text { commercial } \\
\text { SOI wafer }\end{array}$ & MEMS & $\begin{array}{c}1 \text { sun } \\
(\mathrm{AM} 1.5 \mathrm{G})\end{array}$ & $\begin{array}{c}V_{\mathrm{OC}}=103 \mathrm{~V} ; P=3.2 \mathrm{~mW} ; \\
V_{\mathrm{OC}, \text { specific }}=240 \mathrm{~V} / \mathrm{cm}^{2} ; \mathrm{Eff} .=7.6 \% \\
\text { (individual cell: } V_{\mathrm{OC}}=0.622 \mathrm{~V} ; \\
J_{\mathrm{SC}}=22.3 \mathrm{~mA} / \mathrm{cm}^{2} ; P=23 \mu \mathrm{W} ; \\
F F=73.6 \text { and } \text { Eff. }=10.2 \%) ;\end{array}$ & {$[54]$} \\
\hline $\begin{array}{c}\text { p-i-n/p-i-n/p-i- } \\
\text { n a-Si:H } \\
\text { MJSC }\end{array}$ & $\begin{array}{l}100 \text { cells (in } 1 \\
\left.\mathrm{~cm}^{2} \mathrm{MIM}\right)\end{array}$ & $\begin{array}{l}\text { Isolate a- } \\
\text { Si:H } \\
\text { devices }\end{array}$ & $\begin{array}{c}\text { 400nm } \mathrm{SiO}_{2} \\
\text { layer on 3"' } \mathrm{Si} \\
\text { wafer }\end{array}$ & MEMS & $\begin{array}{c}1 \text { sun } \\
(\mathrm{AM} 1.5 \mathrm{G})\end{array}$ & $\begin{array}{c}\quad V_{\mathrm{OC}}=150 \mathrm{~V} ; J_{\mathrm{SC}}=2.8 \mu \mathrm{A} ; \\
\text { (individual cell: } J_{\mathrm{SC}}=2.8 \mathrm{~mA} / \mathrm{cm}^{2} \text {; } \\
F F=0.495 \text { ) }\end{array}$ & [58] \\
\hline $\begin{array}{l}\text { 1J-GaAs thin } \\
\text { film by } \\
\text { CLEFT }\end{array}$ & $\begin{array}{l}44 \mathrm{~cm}^{2} \text { and } 8 \\
0.25 \mathrm{~cm}^{2} \text { series- } \\
\text { connected cells }\end{array}$ & $\begin{array}{c}\text { Insulating } \\
\text { grooves on } \\
\text { SI GaAs }\end{array}$ & $\begin{array}{l}\text { Reusable 3', } \\
\text { single-crystal } \\
\text { GaAs wafer }\end{array}$ & $\begin{array}{l}\text { Terrestrial } \\
\text { and space } \\
\text { solar cells }\end{array}$ & $\begin{array}{c}1 \text { sun } \\
(\mathrm{AM} 1.5 \mathrm{G})\end{array}$ & $\begin{array}{c}44 \mathrm{~cm}^{2} \text { cell MIM: } J_{\mathrm{SC}}=6.5 \\
\mathrm{~mA} / \mathrm{cm}^{2} ; V_{\mathrm{OC}}=4.04 \mathrm{~V} ; \mathrm{FF}=0.8 ; \\
\text { Eff. }=21 \% \\
80.25 \mathrm{~cm}^{2} \text { cell MIM: }: J_{\mathrm{SC}}=3.13 \\
\mathrm{~mA} / \mathrm{cm}^{2} ; V_{\mathrm{OC}}=7.96 \mathrm{~V} ; F F=0.85 ; \\
\text { Eff. }=21.2 \%\end{array}$ & {$[67]$} \\
\hline $\begin{array}{c}\text { 1J-GaAs with } \\
\text { GaInP LCL on } \\
\text { top }\end{array}$ & 6 segments & \begin{tabular}{|c|} 
Insulating \\
grooves on \\
SI GaAs
\end{tabular} & p-GaAs wafer & LPC & $\begin{array}{l}175 \text { suns } \\
(810 \mathrm{~nm} \\
\text { beam })\end{array}$ & $V_{\mathrm{OC}}=6.95 \mathrm{~V} ; \mathrm{Eff} .=43 \%$ & [81] \\
\hline \begin{tabular}{|} 
Vertically- \\
Stacked GaAs \\
cells
\end{tabular} & $\begin{array}{l}5 \text { vertically- } \\
\text { stacked series- } \\
\text { connected cells }\end{array}$ & $\begin{array}{c}\text { Tunnel } \\
\text { junctions }\end{array}$ & GaAs wafer & LPC & $\begin{array}{l}110 \text { suns } \\
(835 \mathrm{~nm} \\
\text { beam })\end{array}$ & $V_{\mathrm{OC}}=5.77 \mathrm{~V} ;$ Eff. $=60.1 \%$ & [83] \\
\hline $\begin{array}{l}1 \mathrm{~J}-\mathrm{GaAs} \text { with } \\
\text { a lower LCL }\end{array}$ & 10 segments & \begin{tabular}{|c|} 
Insulating \\
grooves on \\
SI GaAs
\end{tabular} & GaAs wafer & $\mathrm{CPV}$ & $\begin{array}{l}150 \text { suns / } \\
1,000 \text { suns } \\
(\mathrm{AM} 1.5 \mathrm{G})\end{array}$ & $\begin{array}{l}\text { Eff. }=20.8 \%(150 \text { suns }) \\
\text { Eff. }=17 \%(1,000 \text { suns })\end{array}$ & [87] \\
\hline $\begin{array}{c}1 \mathrm{~J}-\mathrm{GaAs} \text { with } \\
2 \mathrm{LCL} \text { and } \\
\text { bypass diodes }\end{array}$ & $\begin{array}{l}25 \text { segments } \\
\left(10 \times 10 \mathrm{~cm}^{2}\right)\end{array}$ & $\begin{array}{c}\text { Insulating } \\
\text { grooves on } \\
\text { SI GaAs }\end{array}$ & GaAs wafer & $\mathrm{CPV}$ & $\begin{array}{l}199 \text { suns / } \\
962 \text { suns } \\
\text { (AM1.5d) }\end{array}$ & $\begin{array}{c}J_{\mathrm{SC}}=184.6 \mathrm{~mA} / \mathrm{cm}^{2} ; V_{\mathrm{OC}}=29.3 \mathrm{~V} ; \\
F F=0.81 ; \mathrm{Eff} .=22 \% \\
J_{\mathrm{SC}}=889.5 \mathrm{~mA} / \mathrm{cm}^{2} ; V_{\mathrm{OC}}=30.4 \mathrm{~V} ; \\
F F=0.709 ; \mathrm{Eff} .=17 \%\end{array}$ & [89] \\
\hline
\end{tabular}




\begin{tabular}{|c|c|c|c|c|c|c|c|}
\hline \begin{tabular}{|c|}
$1 \mathrm{~J}-\mathrm{GaAs}$ \\
polyimide/SiO \\
$/ \mathrm{TiAu} / \mathrm{SiO}_{2}$
\end{tabular} & 108 & \begin{tabular}{|c|} 
Insulating \\
grooves on \\
SI GaAs
\end{tabular} & GaAs wafer & MEMS & $\begin{array}{c}1 \text { sun } \\
(\mathrm{AM} 1.5 \mathrm{G})\end{array}$ & $\begin{array}{c}J_{\mathrm{SC}}=23.3 \mathrm{~mA} / \mathrm{cm}^{2} ; V_{\mathrm{OC}}=84.2 \mathrm{~V} ; \\
F F=0.57 ; \text { Eff. }=11.2 \%\end{array}$ & [101] \\
\hline \begin{tabular}{|c|}
$1 \mathrm{~J}-$ \\
GaInAsP/InP \\
heterostructure
\end{tabular} & $\begin{array}{l}12 \text { subcells in } \\
\text { radial } \\
\text { configuration }\end{array}$ & \begin{tabular}{|c|} 
Mesa \\
isolation on \\
SI InP
\end{tabular} & InP wafer & LPC & $\begin{array}{c}\sim 10 \text { suns } \\
(1.06 \mu \mathrm{m} \\
\text { light })\end{array}$ & $\begin{array}{c}I_{\mathrm{SC}}=2.25 \mathrm{~mA} / \mathrm{cm}^{2} ; V_{\mathrm{OC}}=7.6 \mathrm{~V} \\
F F=0.76 ; \text { Eff. }=\sim 30 \%\end{array}$ & [103] \\
\hline $\begin{array}{c}\text { 1J-InAlGaAs } \\
\text { with InGaAs } \\
\text { LCL }\end{array}$ & $\begin{array}{l}8 \text { subcells }(1 \\
\left.\mathrm{cm}^{2}\right)\end{array}$ & \begin{tabular}{|c|} 
Isolation \\
grooves on \\
SI InP
\end{tabular} & InP wafer & LPC & $\begin{array}{c}\sim 5.6 \text { suns } \\
(1.3 \mu \mathrm{m} \\
\text { light })\end{array}$ & $\begin{array}{c}J_{\mathrm{SC}}=46 \mathrm{~mA} / \mathrm{cm}^{2} ; V_{\mathrm{OC}}=3.02 \mathrm{~V} ; \\
F F=70 \% ; \text { Eff. }=22 \%\end{array}$ & [106] \\
\hline \begin{tabular}{|c} 
J-InGaAs \\
$(0.74 \mathrm{eV}$ and \\
$0.55 \mathrm{eV})$ with \\
InGaAs LCL
\end{tabular} & $\begin{array}{l}15 \text { subcells } \\
\left(0.9 \times 1 \mathrm{~cm}^{2}\right)\end{array}$ & $\begin{array}{c}\text { Isolation } \\
\text { grooves on } \\
\text { SI InP }\end{array}$ & InP wafer & TPV & $\begin{array}{l}\text { Greybody } \\
\text { radiator at } \\
T=1225 \mathrm{~K})\end{array}$ & $\begin{array}{c}0.74 \mathrm{eV} \text { InGaAs MIM: } J_{\mathrm{SC}}=842 \\
\mathrm{~mA} / \mathrm{cm}^{2} ; V_{\mathrm{OC}}=6.16 \mathrm{~V} ; F F=74.2 \% \\
0.55 \mathrm{eV} \text { InGaAs MIM: } J_{\mathrm{SC}}=3.87 \\
\mathrm{~A} / \mathrm{cm}^{2} ; V_{\mathrm{OC}}=4.85 \mathrm{~V} ; F F=57.8 \%\end{array}$ & [112] \\
\hline \begin{tabular}{|c|}
$\mathrm{n} / \mathrm{p} / \mathrm{n} 1 \mathrm{~J}-$ \\
$\mathrm{InGaAs} / \mathrm{InPAs}$ \\
$(0.55 \mathrm{eV})$ with \\
tunnel junction
\end{tabular} & 30 subcells & $\begin{array}{c}\text { Isolation } \\
\text { grooves on } \\
\text { SI InP }\end{array}$ & InP wafer & TPV & $\begin{array}{l}\text { Unknown } \\
\text { irradiance } \\
\text { (W halogen } \\
\text { lamp) }\end{array}$ & $\begin{array}{c}J_{\mathrm{SC}}=1.15 \mathrm{~A} / \mathrm{cm}^{2} ; V_{\mathrm{OC}}=8.35 \mathrm{~V} ; \\
F F=61 \%\end{array}$ & [119] \\
\hline $\begin{array}{c}\mathrm{n} / \mathrm{p} / \mathrm{n} 1 \mathrm{~J}- \\
\text { InGaAs/InPAs } \\
(0.6 \mathrm{eV}) \text { with } \\
\text { tunnel junction }\end{array}$ & $\begin{array}{l}30 \text { subcells }(4 \\
\left.\mathrm{cm}^{2}\right)\end{array}$ & \begin{tabular}{|} 
Isolation \\
grooves on \\
SI InP
\end{tabular} & 3"' InP wafer & TPV & $\begin{array}{l}950^{\circ} \mathrm{C} \text { gray- } \\
\text { body-like } \\
\text { halogen- } \\
\text { lamp } \\
\text { Radiation }\end{array}$ & $\begin{array}{c}\text { (average data from large sample): } \\
J_{\mathrm{SC}}=2.23 \mathrm{~A} / \mathrm{cm}^{2}( \pm 0.002 \mathrm{~A} / \mathrm{cm} 2) ; \\
V_{\mathrm{OC}}=10.93 \mathrm{~V}( \pm 0.023 \mathrm{~V}) ; \\
F F=68.3 \%( \pm 0.783 \%) ; \\
\text { Eff. }=20.3 \%( \pm 0.27 \%)\end{array}$ & [129] \\
\hline $\begin{array}{l}0.6 \mathrm{eV} 1 \mathrm{~J}- \\
\mathrm{InGaAsSb}\end{array}$ & 15 subcells & $\begin{array}{c}\mathrm{AlGaAsSb} \\
\mathrm{CID}\end{array}$ & $\begin{array}{l}\text { Conductive p- } \\
\text { GaSb wafer }\end{array}$ & TPV & $\begin{array}{c}\text { Flash } \\
\text { illumination }\end{array}$ & $\begin{array}{c}\mathrm{V}_{\text {breakdown }} \sim 5-7 \mathrm{~V} \\
V_{\mathrm{OC}}(1 \text { subcell })=0.2 \mathrm{~V} ; \\
V_{\mathrm{OC}}(\mathrm{MIM})=0.42 \mathrm{~V}\end{array}$ & [134] \\
\hline $\begin{array}{l}\text { 1J-GaInAsSb } \\
\text { on GaSb } \\
\text { wafer-bonded } \\
\text { to GaAs }\end{array}$ & $\begin{array}{c}2 \text { and } 10 \\
\text { subcells } \\
\left(0.05 \times 0.5 \mathrm{~cm}^{2}\right. \\
\text { per subcell })\end{array}$ & \begin{tabular}{|} 
Isolation \\
grooves on \\
SI GaAs
\end{tabular} & $\begin{array}{c}2{ }^{\prime} \mathrm{GaSb} \\
\text { wafer-bonded } \\
\text { to } \mathrm{GaAs} \text { with } \\
\mathrm{SiO}_{\mathrm{x}} / \mathrm{Ti} / \mathrm{Au}\end{array}$ & TPV & - & $\begin{array}{c}2 \text { subcell: } J_{\mathrm{SC}}=0.4 \mathrm{~A} / \mathrm{cm}^{2} \text { leads to } \\
V_{\mathrm{OC}}=0.37 \mathrm{~V} \text { and } J_{\mathrm{SC}}=1 \mathrm{~A} / \mathrm{cm}^{2} \\
\text { leads to } V_{\mathrm{OC}}=0.47 \mathrm{~V} \\
10 \text { subcell MIM: } J_{\mathrm{SC}}=0.4 \mathrm{~A} / \mathrm{cm}^{2} \\
\text { leads to } V_{\mathrm{OC}}=1.8 \mathrm{~V} \text { and } J_{\mathrm{SC}}=1 \\
\mathrm{~A} / \mathrm{cm}^{2} \text { leads to } V_{\mathrm{OC}}=2 \mathrm{~V}\end{array}$ & [135] \\
\hline \begin{tabular}{|c|} 
Inverted 2J- \\
$\mathrm{In}_{0.53} \mathrm{Ga}_{0.47} \mathrm{As} /$ \\
$\mathrm{In}_{0.64} \mathrm{Ga}_{0.36} \mathrm{As}$ \\
$\operatorname{MJSC}(0.74$ \\
$\mathrm{eV} / 0.63 \mathrm{eV})$
\end{tabular} & $\begin{array}{l}10 \text { subcells }(5 \times 5 \\
\left.\mathrm{mm}^{2} \text { per subcell }\right)\end{array}$ & $\begin{array}{c}\text { Isolation } \\
\text { grooves on } \\
\text { SI InP }\end{array}$ & 2" InP wafer & TPV & $\begin{array}{c}1,000^{\circ} \mathrm{C} \\
\text { graybody } \\
\text { source } \\
(\text { emissivity } \\
0.3)\end{array}$ & $\begin{array}{c}J_{\mathrm{SC}}=292 \mathrm{~mA} / \mathrm{cm}^{2} ; V_{\mathrm{OC}}=6.14 \mathrm{~V} \\
F F=67.6 \%\end{array}$ & [150] \\
\hline $\begin{array}{c}2 \mathrm{~J}-\mathrm{InGaAsP} \text { or } \\
\text { AlGaInAs on } \\
\text { InGaAs MJSC } \\
\text { (2 tunnel } \\
\text { junctions used })\end{array}$ & $\begin{array}{l}30 \text { subcells }(2 \times 2 \\
\left.\mathrm{cm}^{2}\right)\end{array}$ & $\begin{array}{l}\text { Isolation } \\
\text { mesas on } \\
\text { SI InP }\end{array}$ & 3' InP wafer & TPV & $\begin{array}{c}\text { Halogen } \\
\text { lamp with } \\
1,925^{\circ} \mathrm{C} \\
\text { equivalent } \\
\text { blackbody } \\
\text { temperature }\end{array}$ & $\begin{array}{c}\text { InGaAsP/InGaAs: } J_{\mathrm{SC}}=30.75 \\
\mathrm{~mA} / \mathrm{cm}^{2} ; V_{\mathrm{OC}}=24.9 \mathrm{~V} ; F F=68.5 \% \\
\mathrm{AlGaInAs} / \mathrm{InGaAs}: J_{\mathrm{SC}}=32.25 \\
\mathrm{~mA} / \mathrm{cm}^{2} ; V_{\mathrm{OC}}=25.1 \mathrm{~V} ; F F=67.6 \%\end{array}$ & [153] \\
\hline \begin{tabular}{|c|} 
2J- \\
GaInP/InGaAs
\end{tabular} & $\begin{array}{c}\text { No data for the } \\
\text { number of }\end{array}$ & $\begin{array}{l}\text { Isolation } \\
\text { trenches }\end{array}$ & GaAs wafer & $\mathrm{CPV}$ & $\begin{array}{c}496 \text { suns } \\
/ 1,028 \text { suns }\end{array}$ & $\begin{array}{c}496 \text { suns: } V_{\mathrm{OC}} \sim 53 \mathrm{~V} ; F F \sim 80 \% ; \\
\text { Eff. }=26 \%\end{array}$ & [154] \\
\hline
\end{tabular}




\begin{tabular}{|c|c|c|l|l|l|l|l|}
\hline $\begin{array}{c}\text { MJSC (2 LCL, } \\
3 \text { tunnel } \\
\text { junctions and } \\
\text { bypass diodes) }\end{array}$ & $\begin{array}{c}\text { subcells (4.368 } \\
\left.\mathrm{cm}^{2}\right)\end{array}$ & $\begin{array}{c}\text { on SI } \\
\text { GaAs }\end{array}$ & & & & (AM1.5d) & $\begin{array}{c}1,028 \text { suns: } V_{\mathrm{OC}} \sim 54.5 \mathrm{~V} ; \\
F F \sim 73 \% ; \text { Eff. }=24.2 \%\end{array}$ \\
\hline
\end{tabular}




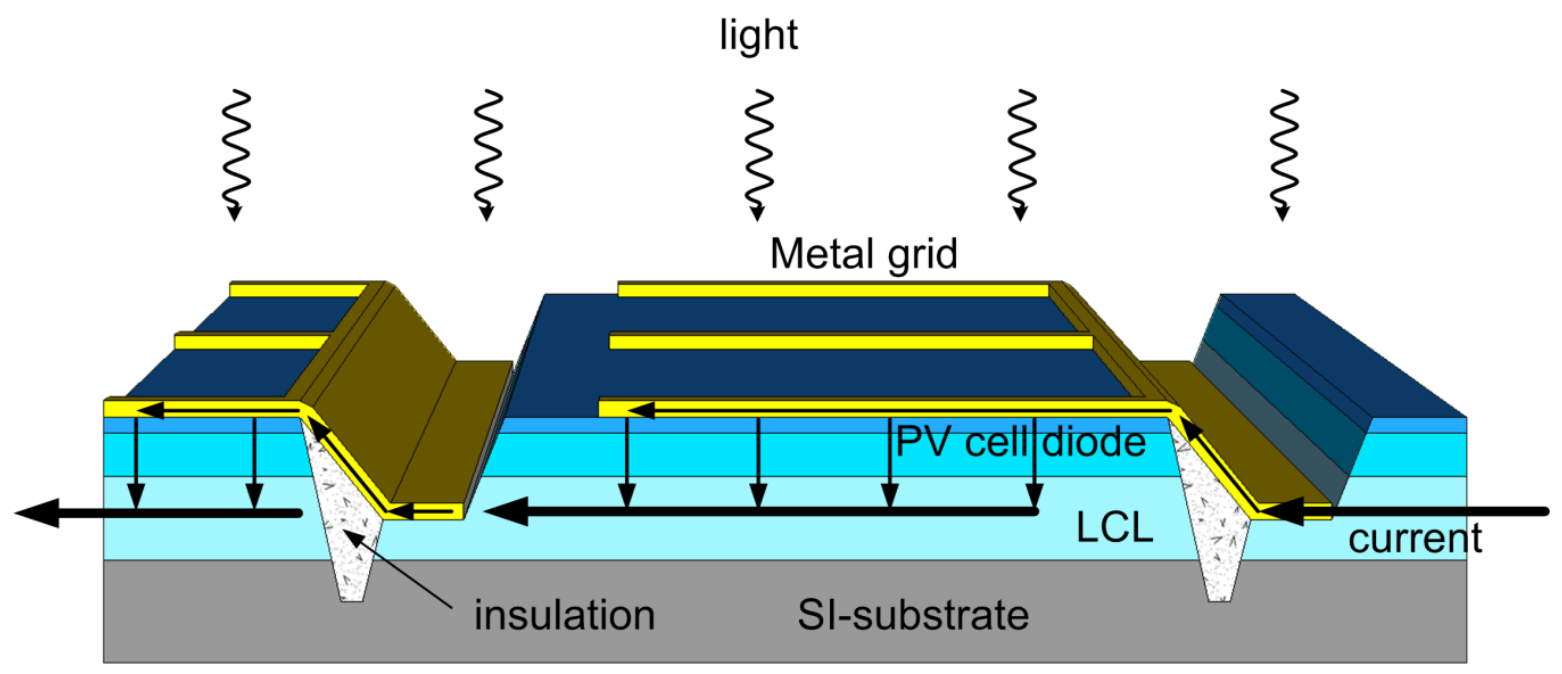

Figure 1. Operation principle of a typical MIM based on SI-substrate 


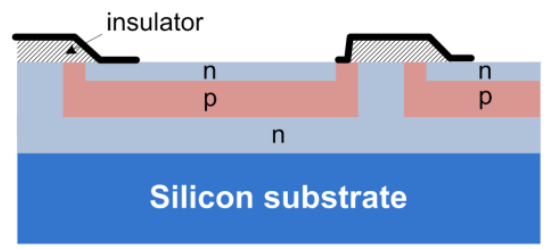

(a)

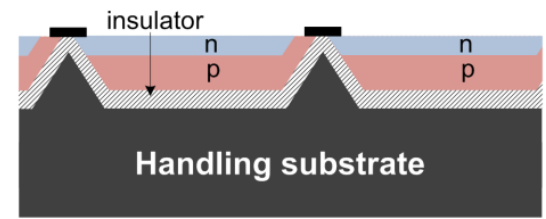

(c)

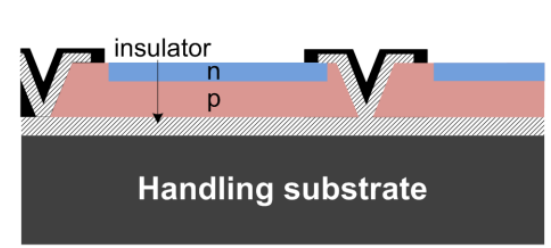

(e)

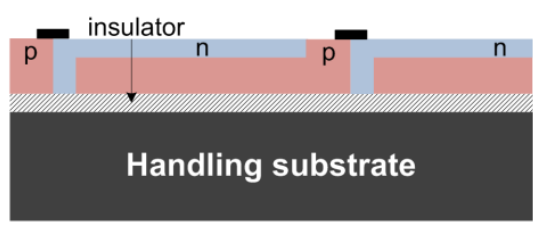

(b)

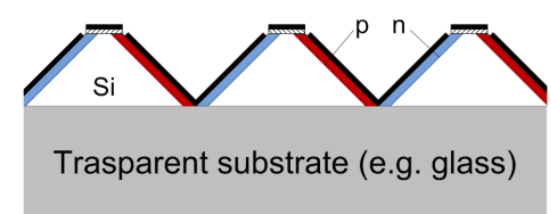

(d)

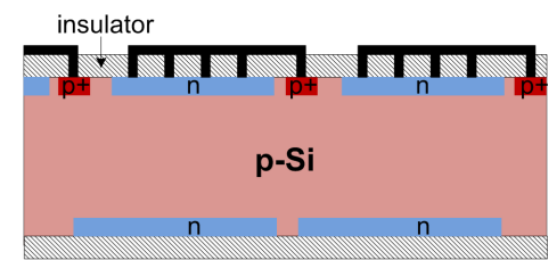

(f)

Figure 2. Si-based MIM designs. 


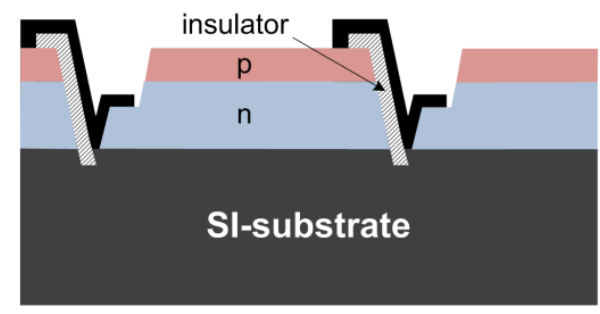

(a)

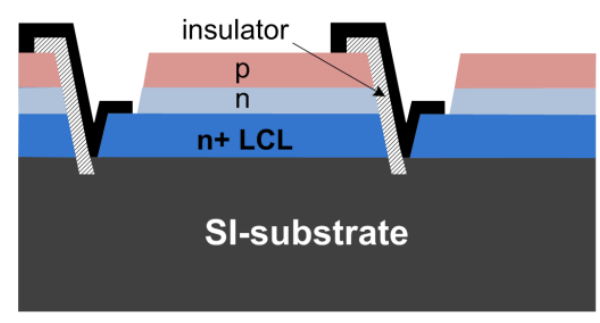

(c)

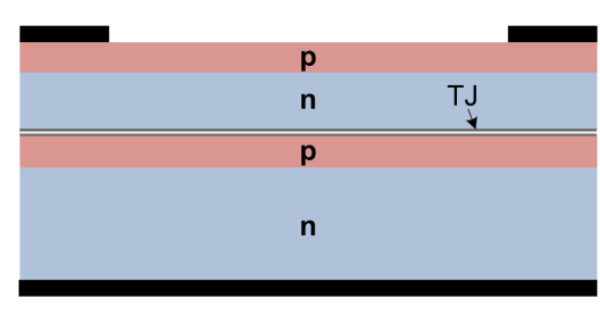

(e)

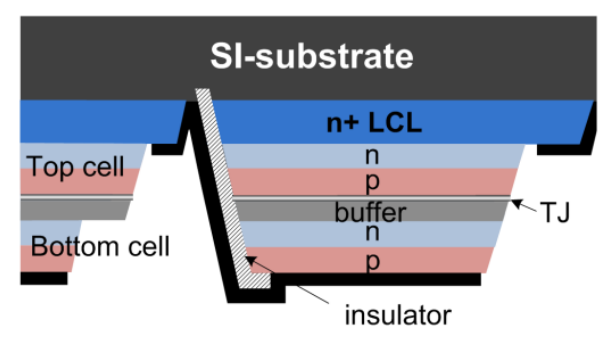

(g)

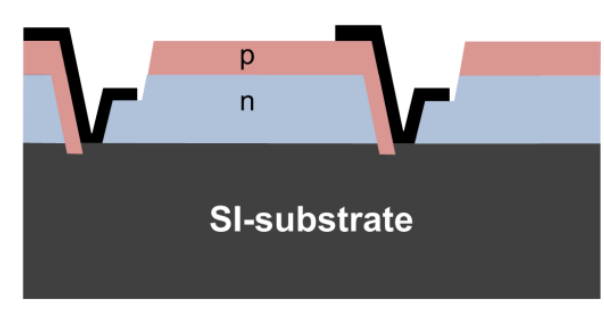

(b)

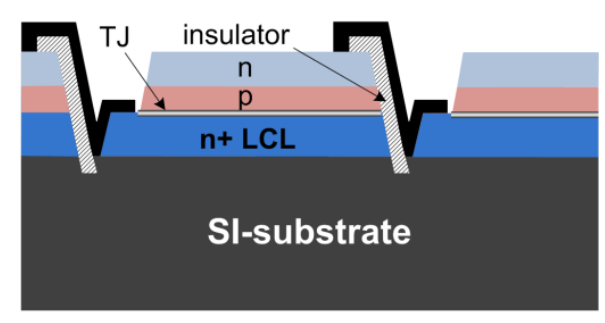

(d)

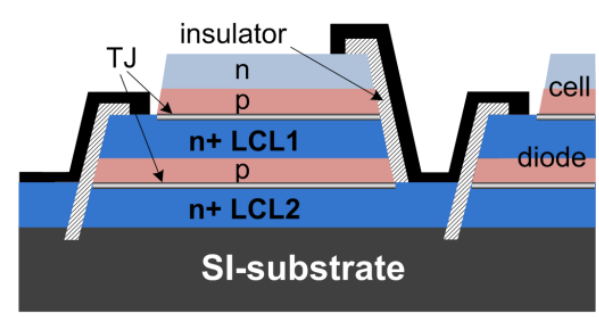

(f)

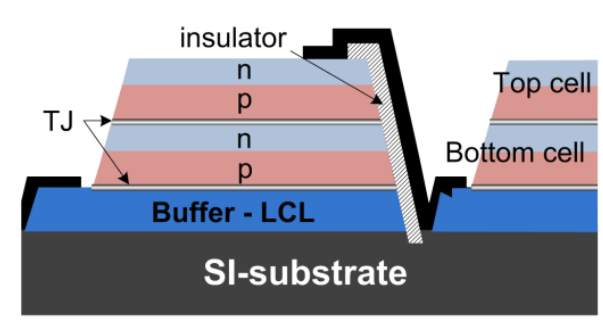

(h)

Figure 3. III-V semiconductor based MIM designs. 
(a)
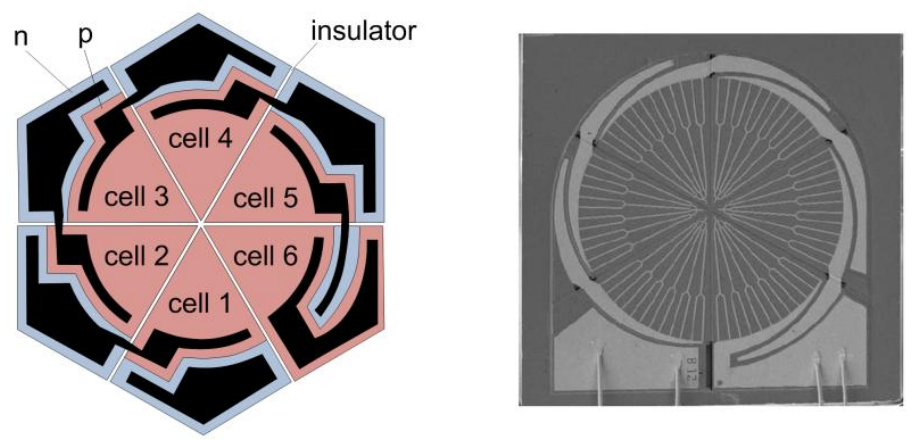

(b)
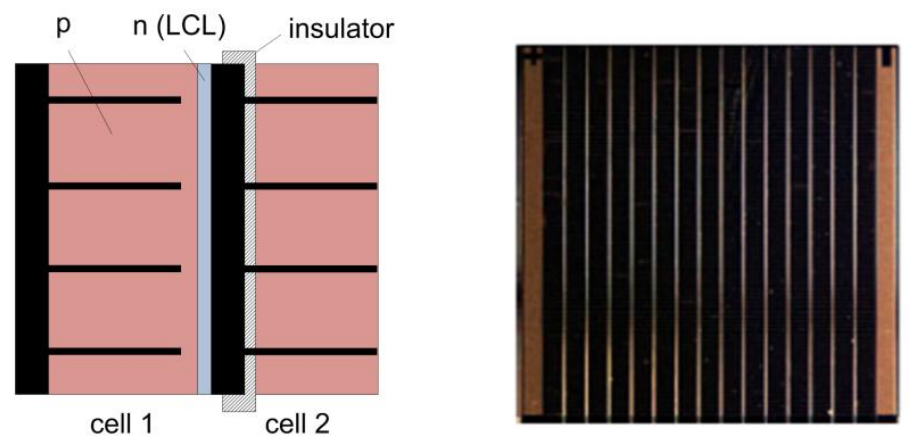

(c)
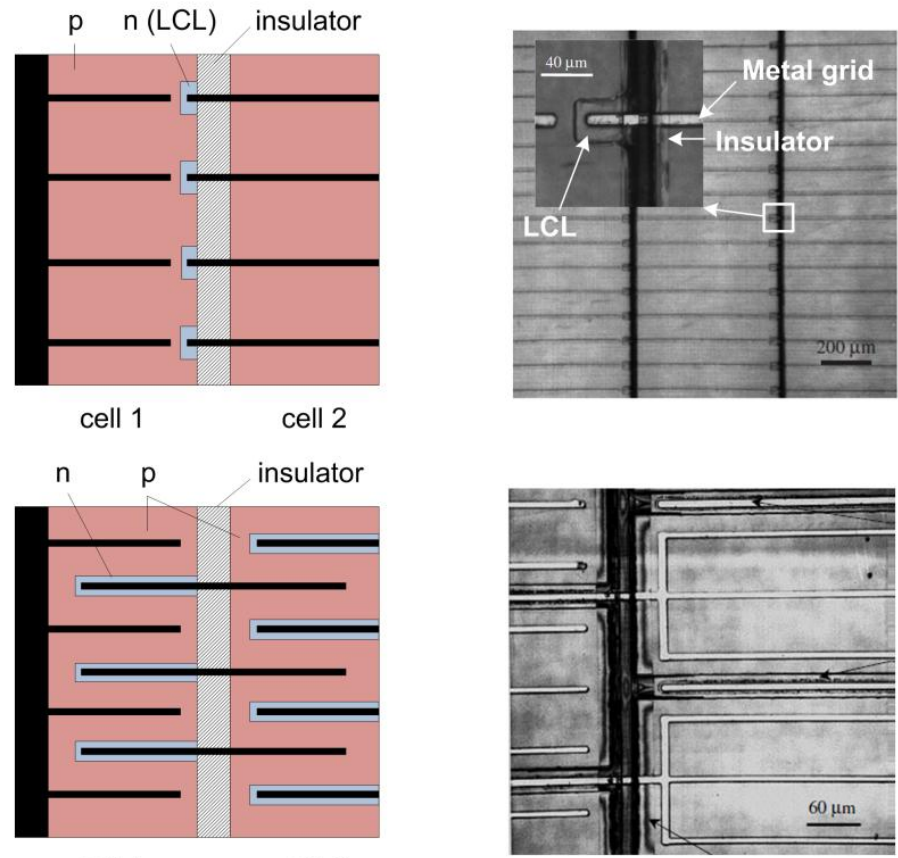

Figure 4. Typical III-V-based MIM layouts for LPC, CPV and TPV applications. (a) LPC MIM layout (reproduced from [82]), (b)-(c) conventional LCL-based MIM layouts for CPV and TPV applications (reproduced from [123]) (d) Interdigitated MIM design (reproduced from [123]). 


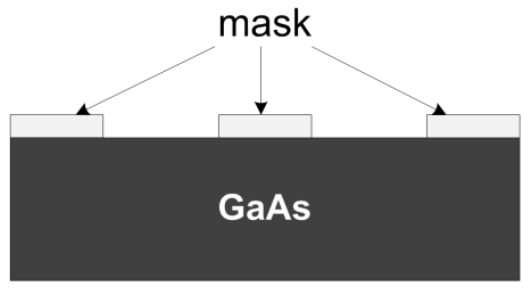

(a)

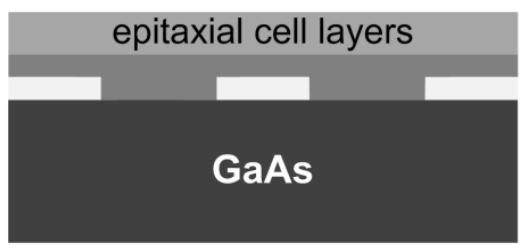

(b)

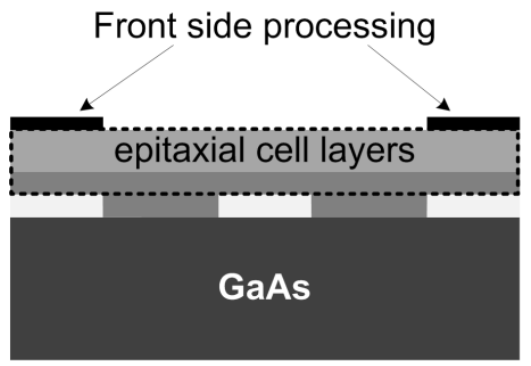

(c)

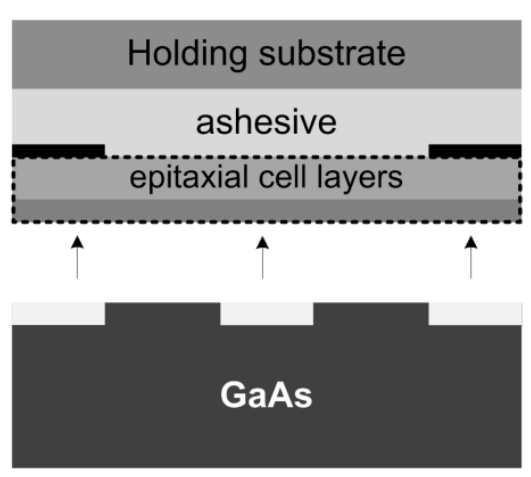

(d)

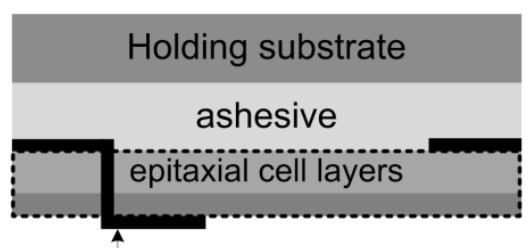

Via hole etching - back side processing

(e)

Figure 5. GaAs MIM devices fabricated by means of CLEFT process, according to reference [67]. 


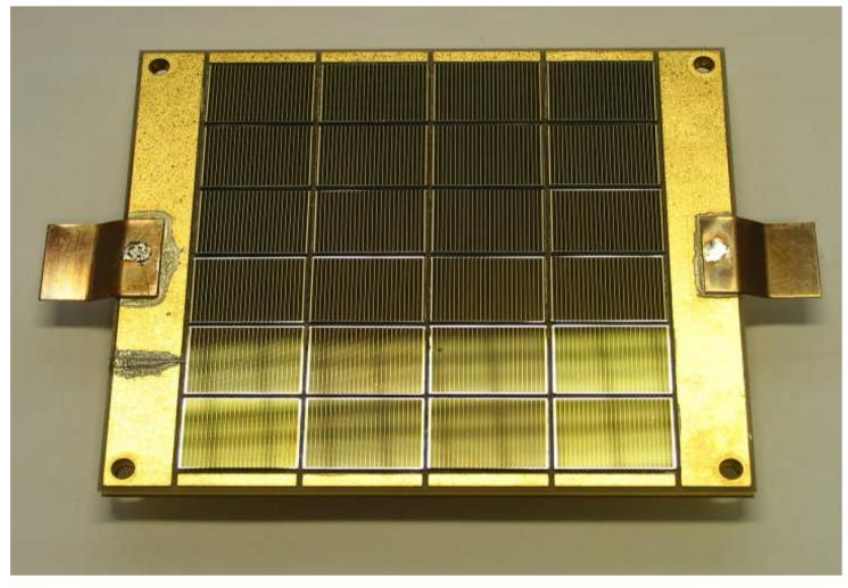

(a)

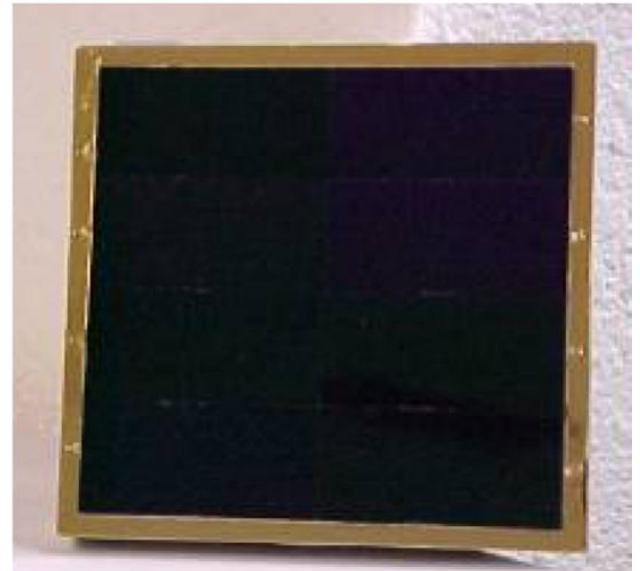

(b)

Figure 6. (a) $10 \times 10 \mathrm{~cm}^{2}$ compact concentrator module (CCM) comprising GaAs MIMs (reproduced from [89]). (b) $10 \times 10 \mathrm{~cm}^{2}$ TPV module comprising $0.6 \mathrm{eV}$ InGaAs MIMs and filter for RTPV applications (reproduced from [131]). 